\title{
Contract Exposition and Formalism
}

\author{
Gregory Klass \\ Georgetown University Law Center, gmk9@law.georgetown.edu
}

This paper can be downloaded free of charge from:

https://scholarship.law.georgetown.edu/facpub/1948

https://ssrn.com/abstract=2913620

This open-access article is brought to you by the Georgetown Law Library. Posted with permission of the author. Follow this and additional works at: https://scholarship.law.georgetown.edu/facpub

Part of the Contracts Commons, and the Jurisprudence Commons 


\section{Contract Exposition and Formalism}

Gregory Klass*

February 2017 - DRAFT

The book of love is long and boring. No one can lift the damn thing.

It's full of charts and facts and figures and instructions for dancing. ${ }^{1}$

The law of contracts addresses three big questions: When does a contract come into existence or disappear? What are the parties' contractual duties, rights, powers and other legal relations? What are the legal consequences of breach? The answer to each generally depends on what the parties said and did, before, during or after formation. A very large portion of contract law therefore involves rules that determine how parties' words and actions effect changes to their legal relations. These are sometimes called "rules of interpretation." For reasons that will be clear below, I will call them rules of exposition. This article is about contract rules of exposition, or the rules that connect what contracting parties say and do to changes in their legal situation.

For over a century US scholars and jurists have been discussing the choice between formalist and contextualist rules of exposition. At the end of the nineteenth century and beginning of the twentieth, Holmes and Williston each advocated plain meaning rules, which focused on the text and its conventional meaning. ${ }^{2}$ Legal Realists like Corbin and Llewellyn criticized that approach and advocated for rules that paid more attention to

\footnotetext{
* Agnes N. Williams Research Professor, Professor of Law, Georgetown University Law Center. I am grateful to lan Ayres for helpful comments on an earlier draft.

${ }^{1}$ Stephin Merritt, The Book of Love, on The Magnetic Fields, 69 Love Songs, Vol. 1 (1999).

2 See Oliver Wendell Holmes, The Theory of Legal Interpretation, 12 Harv. L. Rev. 417, 420 (1899); Samuel Williston, 2 The Law of Contracts, Chapter XXI: General Rules for the Interpretation or Construction of Contracts and the Parol Evidence Rule, 1157-1278 (1920) (hereinafter Williston (1st ed.)).
} 
Klass: Contract Exposition and Formalism

what the words meant in the context in which they were used. ${ }^{3}$ The Realists' influence can be seen in the Second Restatement, ${ }^{4}$ in the UCC, ${ }^{5}$ and in judicial opinions like Justice Traynor's in Pacific Gas \& Electric v. G. W. Thomas Drayage Co. and Judge Friendly's in Frigaliment Importing $v$. B.N.S. International Sales, ${ }^{6}$ both of which are today part of the teaching canon. In the United States, the last decade of the twentieth century saw the resurgence of formalism in contract law, among both academics and jurists. Under the banner of the "New Formalism," scholars marshaled economic analysis and empirical studies to argue that sophisticated parties often preferred more formalist approaches, and that existing rules stood in their way. ${ }^{7}$ At the same time, other scholars and jurists have continued to press for more contextualist rules of contract exposition. ${ }^{8}$

${ }^{3}$ See Arthur Linton Corbin, 3 Corbin on Contracts: A Comprehensive Treatise on the Rules of Contract Law $\S \S$ (1951) (hereinafter "Corbin (1st ed.)"); Arthur L. Corbin, The Interpretation of Words and the Parol Evidence Rule, 50 Cornell L.Q. 161 (1965); K.N. Llewellyn, On Our Case-Law of Contract: Offer and Acceptance I \& II, 48 Yale L.J. 1 \& 779 (1938); K.N. Llewellyn, What Price Contract? - An Essay in Perspective, 40 Yale L.J. 704 (1931).

${ }^{4}$ See, e.g., Restatement (Second) of Contracts §§ 202(1); 212 cmt. b; 214, cmt. b (1981).

${ }^{5}$ See, e.g., U.C.C. §§ 1-303, 2-202, 2-208.

${ }^{6}$ Pacific Gas \& Elec. Co. v. G. W. Thomas Drayage Co., 69 Cal. 2d 33 (1968); Frigaliment Importing Co. v. B.N.S. International Sales Corp., 190 F.Supp. 116 (S.D.N.Y. 1960).

${ }^{7}$ For an early example, see Robert E. Scott, A Relational Theory of Default Rules for Commercial Contracts, 19 J. Legal Stud. 597 (1990). For a recent example, see Ronald J. Gilson, Charles F. Sabel \& Robert E. Scott, Contract and Innovation: The Limited Role of Generalist Courts in the Evolution of Novel Contractual Forms, 88 N.Y.U. L. Rev. 170 (2013). For a good critical overview, see David Charny, The New Formalism in Contract, 66 U. Chi. L. Rev. 842 (1999).

Perhaps the best known judicial statement of the formalist position is Kozinski's criticism of Pacific Gas in Trident Center v. Connecticut Gen. Life Ins. Co., 847 F.2d 564, 569-70 (9th Cir. 1988). But Judge Easterbrook has penned his share, for example in Empro Mfg. Co., Inc. v. Ball-Co Mfg., Inc., 870 F.2d 423 (7th Cir.1989).

${ }^{8}$ See, e.g., Melvin Aron Eisenberg, The Emergence of Dynamic Contract Law, in 2 Theoretical Inq. L. 1 (2001); Eyal Zamir, The Inverted Hierarchy of Contract Interpretation and Supplementation, 97 Colum. L. Rev. 1710 (1997).

For a domestic example of judicial antiformalism, see Teachers Insurance and Annuity Association v. Tribune Co., 670 F.Supp. 491, 499 (S.D.N.Y. 1987). Courts in England have recently taken a sharply 
Klass: Contract Exposition and Formalism

"Formalism" is used with different meanings in different legal contexts. When the subject is not the exposition of legal texts, US scholars often use "formalism" to describe a jurisprudential temperament that prefers rules to standards, abjures consequentialist legal reasoning in favor of deductive systems, would limit the discretion of judges when deciding cases, and would have legal rules operate independently of moral considerations, customs, and other nonlegal norms. ${ }^{9}$ In discussions of legal interpretation or exposition, the term is used more narrowly. Here "formalism" is usually defined in one of two ways: as an interpretive approach that limits the sorts of evidence adjudicators may consider when determining the meaning of legal actors' words and actions, or one that treats meaning as relatively context independent. ${ }^{10}$ These definitions are connected. Limiting the interpretive evidence usually means focusing on written texts and excluding more contextual data. In practice, evidentiary parsimony results in invariant meanings.

These generic definitions of "formalism" are fine as far as they go. But they fail to disaggregate several ways of restricting interpretive evidence and identifying acontextual meanings. This article distinguishes two very different forms of formalism one finds in the law of contract. The first is the use of legal formalities, such as "as is," "F.O.B.," the seal, and established boilerplate. Formalities work only to the extent that context evidence of meaning plays at most a secondary role in their construction. The second, independent, way of limiting context evidence, which I call interpretive formalism, limits the evidence decision makers may consider when they

antiformalist turn, most significantly in Investors Compensation Scheme v. West Bromwich Building Society, [1998] 1 WLR 896; [1998] 1 All ER 98. ${ }^{9}$ See Richard H. Pildes, Forms of Formalism, 66 U. Chi. L. Rev. 607 (1999) (describing the many meanings of "formalism"); Eric A. Posner, The Decline of Formality in Contract Law, in The Fall and Rise of Freedom of Contract 61, 63-64 (F.H. Buckley ed., 1999) (describing ways in which Holmes can be viewed as a formalist); Cass R. Sunstein, Must Formalism Be Defended Empirically?, 66 U. Chi. L. Rev. 636, 638-39 (1999) (describing the formalist attitude).

${ }^{10}$ See, e.g., Sunstein, supra note 9 at 639 (defining "interpretive formalism" in terms of the amount of evidence considered); Avery Weiner Katz, The Economics of Form and Substance in Contract Interpretation, 104 Colum. L. Rev. 496, 516 (2004) (same); Lon L. Fuller, Consideration and Form, 41 Colum. L. Rev. 799 (1941) (describing a "formal transaction" as one that is "abstracted from the causes which gave rise to it and which has the same legal effect no matter what the context of motives and lay practices in which it occurs"); Henry E. Smith, The Language of Property: Form, Context, and Audience, 55 Stan. L. Rev. 1105, 1112 (2003) (treating an expression as "formal to the extent that its meaning is invariant under changes in context"). 
interpret a text, thereby giving greater weight to words' conventional meanings. So-called plain meaning rules are examples of interpretive formalism. Whereas formalities obviate interpretation, interpretive formalism constrains it.

This article does not argue for or against formalism generally, or even for or against one type of formalism. I argue that contract law is too complex for generic arguments of this sort. The law of contracts encompasses a broad range of transactions-everything from an agreement between family members concerning financial and household matters to a long-term supply contract between multinational corporations. The law properly applies different rules of exposition to different transaction types. ${ }^{11}$ In addition, parties' legal situation often depends not on a single act of agreement, but on multiple acts of different types-solicitations, requests for modification, waivers, demands for adequate assurance, repudiations, and so forth. One finds in the law different degrees of formalism depending on the act at issue. Finally, the legal relations that comprise contracts are themselves multifaceted. In addition to first-order duties to perform, a contract might include conditions on those obligations, terms that determine the force of a writing, terms that indicate how the parties' words and actions should be interpreted, limitations on how the contract can be modified, remedial rights and obligations, and so forth. One also finds different types of rules, some more formalist some less formalist, attaching to different legal questions within contractual relationships.

This variety means that lawmakers do not need a single off-the-rack design, but a theory of bespoke design solutions. They do not need generic arguments for or against formalism, but a toolkit for deciding what types of formalism are likely to add value when. This article provides such a theory. Understanding when formalism works in contract law requires a clear account of the structure of contract exposition, differentiation among several types of formalist exposition, and an analysis of the design considerations that speak for and against each.

This article draws both from legal theory and from the philosophy of language. Three ideas from legal theory are especially important: the relationship among mandatory, default and altering rules; the distinction between interpretation and construction; and the concepts of powerconferring rules and juristic acts. Most contemporary contract theorists pay attention only to the first. All three are necessary for an adequate understanding of how contract exposition works. I draw on to ideas from the philosophy of language. The first is the distinction is between what a person says and what she believes and intends, or more technically, between communicative content and propositional attitudes. Unlike much public law, both can be relevant to contract exposition. The second is the

${ }^{11}$ For more on this point, see Hanoch Dagan \& Michael Heller, The Choice Theory of Contract (2017). 
difference between words' literal meaning and what they are used to mean on a given occasion, or more technically, between semantic and pragmatic content. Here too one finds a difference from public law, where semantic content is typically given more weight. If these concepts are not familiar to the reader, they will be by the end of this article. They allow me to distinguishing and provide detailed descriptions of the two basic forms of formalism, and to examine when lawmakers should deploy each.

Philosophers distinguish between knowing how and knowing that. ${ }^{12}$

One can know how to speak English, for example, without knowing that an indirect object usually comes before the direct object ("I gave her it."), but not when preceded by a "to" ("I gave it to her."). This article provides something like a grammar of the rules of contract exposition. It employs concepts that are more fine-grained than the ones courts typically use, and describes what courts do rather than what they say. In that respect, it is speaks in the first instance to theorists of the law, rather than users of it.

That said, many of the ideas I employ have forgotten precursors in the classic treatises, and especially in early editions of Wigmore, Williston and Corbin-writers who exerted an enormous influence on the development of our law of contract and whose contributions I discuss in the analysis below. And of course theory is not divorced from practice. Knowing that formalist rules of contract exposition have a certain function and structure can improve how we design and deploy them. In the course of developing a general theory of formalism, this article provides new accounts of some important cases and familiar topics. These include a close reading of Justice Traynor's opinion in Pacific Gas (section 3.2.3), a new analysis of so-called plain meaning rules (section 2.2.3), a critical discussion of common arguments against the very possibility of plain meaning (section 3.2.1), and a new account of the parol evidence rule, and especially the rules for integration (Part Four).

The remainder of this article proceeds as follows. Part One provides the conceptual tools necessary for the analysis. These include: the distinction between interpretation and construction; an understanding of the difference between mandatory rules, default rules and altering rules; and a sharp distinction, new in the literature, between interpretive and formalistic altering rules. Part Two uses these ideas to describe two forms of formalism in contract law. The first involves the use of legal formalities, which obviate interpretation altogether. The second, typified by plain meaning rules, limits interpretive evidence and thereby gives greater weight to the literal meaning of parties' words. Part Three then asks when lawmakers might want to deploy one or another form of formalism. This is not an argument for or against formalism, but a theory of how such arguments should be framed and the considerations they should address.

\footnotetext{
${ }^{12}$ Most famously, Gilbert Ryle, Knowing How and Knowing That: The Presidential Address, 46 Proc. Aristotelian Soc'y 1 (1945-46).
} 
Klass: Contract Exposition and Formalism

Part Four applies the analysis to critically examine the parol evidence rule, focusing on the rules for determining whether or not a writing is integrated.

Before jumping into the analysis, two comments, one on substance and the other on method. First, readers who know contract law might wonder why I do not spend more time on the distinction between subjective and objective meaning. Although the distinction played an outsize role in thinking about contract interpretation at the turn of the twentieth century, I give it only a paragraph in section 2.2.1.2. The reason is that I believe the distinction is not very salient in practice and of limited interest in theory. It is primarily a rule for assessing relative fault when there was an alleged miscommunication. For readers who are concerned about the distinction, I suggest reading my unmodified uses of "meaning," "communicative content," "belief," "interpretation," and similar concepts in their objective senses.

Second, this article explores the rules of contract interpretation and construction from within, taking lawmakers' stated reasoning and rationales largely at face value. It does not, on the whole, examine how courts actually apply those rules or ask what hidden purposes they might serve. ${ }^{13}$ Although I am not uncritical of existing practices, I examine them from the inside. The hope is that a clear functional analysis of the rules courts articulate, one that clarifies both their internal logic and their empirical presuppositions, will assist in identifying both those rules' limits and their misapplications. Part Four's analysis of the parol evidence rule provides an example.

\section{Legal Exposition: Some Basic Concepts}

A large portion of the law of contracts comprises rules governing how parties' words and actions effect changes to their legal relationship. These include rules that govern when a contract comes into existence, such as the rules for what constitutes an offer, acceptance, counteroffer, rejection or agreement; rules for determining from parties' agreement the scope of their contractual duties, rights, privileges, powers, and so forth; rules for contract modifications and waivers; rules for anticipatory repudiation and adequate assurances; and rules governing the election of remedies. These and other rules specify how parties' words and actions can alter the legal situation between them.

This mutability of parties' contractual relationships is a defining feature of contract law. Sophisticated parties have an enormous amount of control over when contractual obligations attach, what those obligations

${ }^{13}$ See, e.g., Eyal Zamir, The Inverted Hierarchy of Contract Interpretation and Supplementation, 97 Colum. L. Rev. 1710 (1997) (arguing that in practice courts do not follow the rules of interpretation and construction they articulate). 
are, and the consequences of their breach. Parties even have the power to change the rules that govern how future changes can be made. Thus an offer can stipulate what counts as an acceptance; a no-oral-modification clause can alter how parties can make changes to their contract; a merger clause can limit the evidence that will go into determining the scope of the parties' contractual obligations. All this and more is done through communicative acts. Usually these are linguistic acts, although sometimes other meaningful acts or omissions suffice.

In order to avoid confusion, I use legal exposition to refer to the process of translating persons' words and actions into legal effects. This article is about how legal exposition works in contract law, and about a family of rules of contract exposition that can be broadly described as "formalist." But first I need to say a few words about the structure of contract exposition more generally. Three features are foundational for the discussion that follows.

The first is the difference between two activities that go into legal exposition: interpretation and construction. Arthur Linton Corbin's description of each in the first edition of his contracts treatise remains one of the best:

By "interpretation of language" we determine what ideas that language induces in other persons. By "construction of the contract," as the term will be used here, we determine its legal operation-its effect upon the action of courts and administrative officials. If we make this distinction, then the construction of a contract starts with the interpretation of its language but does not end with it; while the process of interpretation stops wholly short of a determination of the legal relations of the parties. ${ }^{14}$

Interpretation identifies the meaning of some words or actions, construction their legal effect. For example, it is one thing to determine that a reasonable person would understand an offer made over drinks as a joke, another to determine whether such a joke created the power of acceptance. ${ }^{15}$ It is one thing to determine whether the parties agreed to liquidate damages in a certain amount for breach, another to determine whether that amount is a penalty and therefore cannot be awarded..$^{16}$ It is one thing to determine that the parties adopted a writing as "a complete and exclusive statement of the terms of their agreement," another to determine what evidence they can therefore use to prove the terms of the contract, and how they may use it. ${ }^{17}$ In each of the examples, the first activity is interpretation, the second

${ }^{14} 3$ Corbin (1st ed.) $\S 534$ at 7.

${ }^{15}$ See, e.g., Lucy v. Zehmer, 196 Va. 493 (1954).

${ }^{16}$ See Restatement (Second) of Contracts $§ 356$ (1981).

${ }^{17}$ Restatement (Second) of Contracts $\S 210(1)$ (1981). 
construction. Rules of interpretation govern the identification of meaning; rules of construction the determination of legal effect. Legal exposition, as I am using the term, comprises interpretation and construction.

The second structural feature is the difference between mandatory rules, default rules and altering rules, all of which are rules of construction. A mandatory rule specifies a legal state of affairs that applies no matter what legal actors say and do. Thus when the Second Restatement observes that "[e]very contract imposes upon each party a duty of good faith and fair dealing in its performance and its enforcement," it says that the parties who have entered into a contract have a duty of good faith no matter what. ${ }^{18}$ The duty cannot be disclaimed. A default rule specifies the legal state of affairs absent the right person's or persons' expression to the contrary. Familiar examples in contract law include the rule that an offer on which the offeree has not relied is revocable; ${ }^{19}$ the implied warranty of merchantability that attaches to a merchant's sale of goods; ${ }^{20}$ and most rules governing the calculation of damages for breach. ${ }^{21}$ An altering rule specifies whose saying of what is sufficient to effect a change from the associated default legal state of affairs. ${ }^{22}$ Thus a merchant selling goods can make her offer irrevocable for up to three months by expressing her intent to do so in a signed writing; ${ }^{23}$ a seller can disclaim the implied warranty of merchantability by using words like "as is" or "with all faults", ${ }^{24}$ and parties can generally agree to liquidate or limit damages for breach by expressing their shared intent to do so.

Every default comes with an altering rule. To describe a legal state of affairs as a default is to say that some legal actor or actors might change it by saying the right thing in the right way. Who must say what how is determined by an altering rule. Some altering rules specify the use of particular words or phrases, such as "as is." Others are more open ended. Thus the basic formation rule under Article Two of the Uniform

${ }^{18}$ Restatement (Second) of Contracts $\S 205$ (1981). This is not to say that the parties cannot alter the specific requirements of that obligation through their words and actions. The point is only that they cannot escape the duty altogether.

${ }^{19}$ See Restatement (Second) of Contracts $\S 42 \mathrm{cmt}$. a (1981).

${ }^{20}$ U.C.C. § 2-314(1).

${ }^{21}$ See Restatement (Second) of Contracts §§ 346-52 (1981).

${ }^{22}$ I take this term from lan Ayres's important work, Regulating Opt-Out: An Economic Theory of Altering Rules, 121 Yale L.J. 2032 (2012). See also Brett McDonnell, Sticky Defaults and Altering Rules in Corporate Law, 60 SMU L. Rev. 383 (2007). In earlier work, I have analyzed altering rules under the heading of "opt-out" rules. Gregory Klass, Intent to Contract, 95 Va. L. Rev. 1437 (2009).

${ }^{23}$ U.C.C. § 2-205.

${ }^{24}$ U.C.C. § 2-316(3)(a). 
Commercial Code provides that "[a] contract for sale of goods may be made in any manner sufficient to show agreement." 25 This rule requires only that parties express their agreement to the transaction.

Scholars often speak of default rules as "rules of interpretation," and commonly use terms like "default interpretations" or "interpretive defaults. ${ }^{26}$ But if we attend to the distinction between interpretation and construction, it is clear that both default and altering rules are rules of construction. A default rule says what the legal state of affairs is when the associated altering rule is not satisfied. As Corbin observes, "[w] hen a court is filling gaps in the terms of an agreement, with respect to matters that the parties did not have in contemplation and as to which they had no intention to be expressed, the judicial process .... . may be called 'construction'; it should not be called 'interpretation.'" ${ }^{27}$ Similarly, altering rules describe the legal effects of what parties say and do. As such, they too are rules of construction.

Interpretation enters into legal exposition by way of altering rules. Recall again Article Two's general formation rule: "A contract for sale of goods may be made in any manner sufficient to show agreement, including conduct by both parties which recognizes the existence of such a contract." ${ }^{28}$ Determining whether the parties have agreed to a sale of goods requires interpreting their words and conduct. The altering rule specifies that words or actions with the right meaning will effect a legal change.

All altering rules share a tripartite structure. An altering rule provides that if (1) the right actors (2) perform the right type of act, then (3) a specified nondefault legal state of affairs will pertain. Article Two's rule for firm offers not supported by consideration provides a useful example. The default rule for offers is that they are revocable. Or as I will say below, the defeasible legal effect of simple offer is that the offeror has the power to revoke. Section 2-205 provides an altering rule:

An offer by a merchant to buy or sell goods in a signed writing which by its terms gives assurance that it will be held open is not revocable, for lack of consideration, during the time stated or if no time is stated for a reasonable time, but in no event may such period of irrevocability exceed three months.

The rule establishes (1) whose acts are relevant: those of a merchant buyer or seller of goods; (2) what acts are sufficient to displace the default: a

${ }^{25}$ U.C.C. $\S 2-204(1)$.

${ }^{26}$ A search of Westlaw's JLR database finds 76 articles using "default interpretation," 81 using "interpretive default," and 56 using "default rule of interpretation." Search run on January 13, 2017.

273 Corbin ( 1 st ed.) $\S 534$ at 9.

${ }^{28}$ U.C.C. $\S 2-204$. 
signed written assurance that the offer will be held open; and (3) the term that substitutes for the default: irrevocability for the time stated or, if no time is stated, for a reasonable time, but in no case for more than three months. This article focuses on the second element of altering rules: the specification of acts sufficient to displace the default, which I will call altering acts. I will also say a few things about legal effects.

A merchant's section 2-205 offer must satisfy three requirements. The offer must (a) "by its terms gives assurance that it will be held open," (b) be in writing, and (c) be signed. Determining whether the first requirement is met-whether the right sort of assurance was giveninvolves interpretation, even if only to ascertain the literal meaning of the offeror's words. Determining whether the second and third requirements are satisfied-whether the assurance was in writing and whether it was signed-does not involve interpretation. The first requirement is that the offer perform an act with the right meaning, the second and third that the act be of the right form.

These elements of section 2-205's rule for firm offers reflect a third structural feature of legal exposition. I will call rules that condition legal outcomes on the meaning of what the parties say and do interpretive components of altering rules, and rules that condition legal outcomes on facts that can be ascertained without interpretation formal components. An interpretive component requires interpretation of the parties' words and actions to determine whether they have effected a legal change. A formal component requires examination of formal qualities of the parties' words and actions.

Any given altering rule might have only interpretive components, only formal components, or a mix of the two. I will say that an altering rule that includes only formal components is a formalistic altering rule. Consider section 2-319 of the Code, which provides that, "when the term is F.O.B. the place of shipment, the seller must at that place ship the goods in the manner provided in this Article . . . and bear the expense and risk of putting them into the possession of the carrier." According to this rule, the letters "F.O.B." plus the name of a place suffice to effect the legal change. No further inquiry into what the parties or their words meant is required. The rule is a formalistic one. The section 2-316 rule for "as is" and "with all faults" is similarly formalistic. It provides that, ceteris paribus, the mere use of those words is enough to exclude all implied warranties. So too the common law and statutory rules governing the legal effect of the seal.

I will say that an altering rule that is not formalistic is an interpretive rule. Interpretive altering rules always contain an interpretive component. Their application requires interpretation of the meaning of the parties' words and actions.

An interpretive altering rule might or might not also include formal components. Interpretive rules that also have one or more formal components are mixed interpretive rules. The section 2-205 rule for firm 
offers is a mixed interpretive rule. It requires both that a merchant seller say words with the right meaning-that the offer "by its terms gives assurances that it will be held open" — and that those words be in the right form—-in a signed writing." A merchant's offer must satisfy both the interpretive and the formal components to be a firm offer pursuant to the rule. Pure interpretive rules contain no formal component. Thus the Second Restatement defines an offer as any "manifestation of willingness to enter into a bargain." ${ }^{29}$ It does not condition the existence of an offer on any formal qualities of the act, such as the production of a writing, a signature, or the use of certain words. Along the same lines is the section 2-204 rule: "A contract for sale of goods may be made in any manner sufficient to show agreement, including conduct by both parties which recognizes the existence of such a contract." Although other provisions in the Code add formal components for some contract types, ${ }^{30}$ this basic formation rule is purely interpretive. All that is necessary is that the parties' words and conduct "show agreement" to the exchange.

The distinction between formal and informal components therefore produces a typology of altering rules that can be represented in a two-bytwo table.

Figure 1

Interpretive Component

\begin{tabular}{|c|c|c|c|}
\hline \multirow{2}{*}{\multicolumn{2}{|c|}{ Yes }} & Yes & $\mathrm{No}$ \\
\hline & & $\begin{array}{c}\text { mixed } \\
\text { interpretive rules } \\
\text { (UCC rule for firm } \\
\text { offers) }\end{array}$ & $\begin{array}{l}\text { formalistic rules } \\
\text { ("as is," "F.O.B.") }\end{array}$ \\
\hline $\begin{array}{l}\text { Formal } \\
\text { Component }\end{array}$ & No & $\begin{array}{c}\text { pure } \\
\text { interpretive rules } \\
\text { (generic rules for } \\
\text { agreement) }\end{array}$ & \\
\hline
\end{tabular}

The above discussion can be summarized as follows. Much of contract law concerns the exposition of parties' words and action. Legal exposition involves two separate activities: interpretation, which identifies the meaning of the parties' words and actions, and construction, which identifies their legal effect. Rules of construction include mandatory, default and altering rules. A mandatory rule says what the legal state of affairs is no matter what the parties say or do. A default rule says what the legal state of

${ }^{29}$ Restatement (Second) of Contracts § 24 (1981).

${ }^{30}$ Most obviously the Code's Statute of Frauds. U.C.C. § 2-201. 
affairs is absent the parties' contrary expression. An altering rule identifies contrary expressions sufficient to effect a change from the default. Altering rules can have interpretive and formal components. Interpretive components condition legal change on the performance of acts with the right meaning. Formal components condition legal change on the performance of acts of the right form. Formalistic altering rules have only formal components. Pure interpretive rules have only interpretive components. Mixed interpretive rules have both formal and interpretive components.

Conceptual distinctions and taxonomies are of value when they shed new light on old questions. The argument for the above categories can therefore be found in the remainder of this article. That said, here is an example of their utility. Eric Posner has suggested that "[a]n interesting aspect of the Statute of Frauds and other contract formalities is that they do not fit easily into the default-immutable rule dichotomy frequently used by contract theorists." ${ }^{\prime 11}$ The reason is that the default-immutable rule, or default-mandatory rule, dichotomy is incomplete. Statutes of Frauds and other formal requirements belong to a third category: altering rules. A writing requirement like a Statute of Frauds is not itself an altering rule, but is sometimes a component of other altering rules. In the transactions to which it applies, a Statute of Frauds adds a formal component to the altering rules governing formation: the parties' agreement must be evidenced by a signed writing. ${ }^{32}$ Altering rules and their components, like any other framework contract rules, can themselves be mandatory or default. As it happens, Statutes of Frauds are mandatory components of the altering rules into which they figure. Parties cannot contract out of their writing requirements. Although a complete understanding of such formal requirements demands a richer conceptual toolkit, a Statute of Frauds therefore also fits "into the default-immutable rule dichotomy."

\section{Two Forms of Formalism}

As I noted in the Introduction, scholars and jurists commonly speak about formalist interpretation as if it were just one thing. "Formalism" is

${ }^{31}$ Eric A. Posner, Norms, Formalities, and the Statute of Frauds: A Comment, 144 U. Pa. L. Rev. 1971, 1981 (1996).

${ }^{32}$ This is roughly the basic requirement of Article Two's writing requirement. U.C.C. § 2-201(1). The rule in section 2-201 of the Code contains exceptions and qualifications that are not captured in the above. And other Statutes of Frauds require additional things of the writing. For example, the Second Restatement suggests that the contents of the writing must (1) reasonably identify the subject matter of the contract; (2) indicate that a contract has been made; and (3) state the essential terms of the unperformed promise. Restatement (Second) Contracts § 131 (1981). 
Klass: Contract Exposition and Formalism

defined either as an approach that limits the sorts of evidence that go into interpretation or as one that treats meaning as context independent. ${ }^{33}$ The above description of the structure of legal exposition provides the tools for a more detailed account of the different forms of formalism one finds in the law of contract. This Part describes two common types: formalities and plain meaning rules.

\section{$2.1 \quad$ Formalities}

I have distinguished between interpretive and formal components of altering rules. An interpretive component conditions legal change on words or actions with the right meaning. A formal component conditions legal change on words or actions of the right form. A formalistic altering rule has only formal components; it conditions legal change only on the formal properties of what the parties say and do, not on its meaning.

I will use formalities to denote altering acts that satisfy formalistic altering rules. A formality is an act, such as the use of a specific string of word, a symbol or a gesture, sufficient to effect legal change solely by virtue of its formal qualities, as distinguished from its meaning. The contract formality par excellence is the seal. There is no reason to affix a printed wafer or to add the words "Locus Sigilli" or the letters "L.S." at the bottom of a written agreement except to achieve the associated legal effect. When it was strictly applied, mere compliance with the formal requirements-a writing signed, sealed, and delivered-was enough to create a legal obligation. Thus Williston reported in the first edition of his treatise: "If the forms are observed, the obligation is binding. ... [A]t common law mutual assent or any intention on the part of either obligor or obligee was entirely unnecessary." ${ }^{34}$ This description of the rule for formal contracts, however, does not capture its function. As a formality, the seal provided a means for individuals to realize their intent to incur a legal obligation. An interpretive inquiry into "mutual assent or any intention on the part of either obligor or obligee" was unnecessary because use of the formality itself so strongly evinced the requisite intent. ${ }^{35}$

Legal formalities are familiar creatures. Ian Ayres calls them "passwords"; Charles Goetz and Robert Scott refer to them as "invocations"; and Karl Llewellyn terms them "formal acts." ${ }^{36}$ In Rudolf von

${ }^{33}$ See supra n. 10.

${ }^{34} 1$ Williston (1st ed.) $\S 205,412$.

${ }^{35}$ The seal is still operative in many U.S. jurisdictions, although its legal effect has changed over time. See Eric Mills Holmes, Stature \& Status of a Promise Under Seal as a Legal Formality, 29 Willamette L. Rev. 617 (1993). ${ }^{36}$ Ayres, supra note 22, at 2080-83; Charles J. Goetz \& Robert E. Scott, The Limits of Expanded Choice: An Analysis of the Interactions Between Express and Implied Contract Terms, 73 Cal. L. Rev. 261, 282 (1985); K.N. 
Ihering's canonical explanation, "legal formalities relieve the judge of an inquiry whether a legal transaction was intended, and-in case different forms are fixed for different legal transactions-which was intended." ${ }^{\prime 37}$ Formalistic altering rules achieve this by circumventing interpretation altogether.

Although in their application formalities relieve courts from interpreting the parties' intent, the function of a legal formality is to provide a cheap and effective tool with which parties can realize their intent. As Lon Fuller observed, "form offers a legal framework into which the party may fit his actions, or, to change the figure, it offers channels for the legally effective expression of intention." ${ }^{38}$ Interpretive inquiries into parties' intentions can be uncertain and their results difficult to predict. By rendering interpretation of the parties' intentions unnecessary, a formalistic altering rule gives the parties an instrument for realizing those intentions.

The seal, like the letters "F.O.B" on a contract for the sale of goods, is a pure formality: although it has a history, it has no contemporary meaning other than the legal one defined by the relevant altering rule. Other formalities are constructed out of ordinary language. As already noted, Article Two provides that "unless the circumstances indicate otherwise, all implied warranties are excluded by expressions like 'as is' [or] 'with all faults. '" 39 Although the rule is written as if the phrases are mere examples, in practice it establishes these ordinary-language terms as sufficient to achieve the relevant legal effect. ${ }^{40}$ Sophisticated parties who encounter "as is" in a contract know that it is not being used to convey its non-legal meaning (arguably a tautology), but is there solely to achieve a particular legal effect.

Another salient example comes not from contract law, but the construction of wills. James Bradley Thayer, in his 1898 evidence treatise, described the rule for construing a bequest to the testator's "children":

Llewellyn, What Price Contract? - An Essay in Perspective, 40 Yale L.J. 704, 711 (1931).

${ }^{37}$ Rudolf von Ihering, II Geist des Römischen Rechts 494 (8th ed. 1923) (quoted in Lon L. Fuller, Consideration and Form, 41 Colum. L. Rev. 799, 801 (1941)). See also Joseph Raz, Voluntary Obligations and Normative Powers (pt. 2), in 46 Proc. Aristotelian Soc'y 79, 81 (Supp. 1972) (describing the function of legal formalities). ${ }^{38}$ Lon L. Fuller, Consideration and Form, 41 Colum. L. Rev. 799, 801 (1941).

${ }^{39}$ U.C.C. $\S 2-316(3)(a)$.

${ }^{40}$ See, e.g., Meyer v. Alex Lyon \& Son Sales Managers \& Auctioneers, Inc., 889 N.Y.S.2d 166 (1st Dept. 2009) (holding that "as is" clause disclaimed all implied warranties without further inquiry. 
Facts tending very strongly to show that the testator meant to include the illegitimate children are generally irrelevant, because, prima facie, the legal definition of the term children excludes illegitimates, and therefore a contrary interpretation is not in general legally allowable. ${ }^{41}$

In the language I have been using, at common law the legal consequences of a bequest to one's "children" did not require interpretation of the term. No matter what the word's dictionary meaning or the testator's apparent or actual intentions, the legal effect of word in a last will and testament was that the bequest went only the testator's children by marriage. The example is interesting for three reasons. First, it is an example of a noun serving as legal formality. "As is," "F.O.B." and the seal, in contrast, all stand in for legal propositions or adverbial phrases. Second, the rule nicely illustrates how public policy considerations-here ones that most would today find unacceptable-can figure into the design of legal formalities. The point of the rule was not, or not only, to get at the testator's intent. I briefly consider other purposes formalities can serve in section 3.1.2.

Third, the rule's history illustrates different types of legal effects that can attach to formalities, and to altering acts more generally. In Thayer's description, a bequest to one's "children," without further qualification meant one's children by marriage, no matter what else that testator said. Using the word "children" had a mandatory legal effect-one that the testator could not change. I will call altering acts with mandatory legal effects nondefesaible. Wigmore, discussing the same rule, reports that in later years "the rule seemed to form that whenever a word of relationship was used, the law's meaning could be overthrown when a different sense clearly appeared from the will and when there were no persons who corresponded exactly to the law's meaning." ${ }^{\prime 2}$ This suggests that later courts treated "children" as a defeasible legal formality-one with default legal effects. A bequest to one's children created a presumption that the assets in question were to go only to children by marriage, which could be defeated by interpretive evidence of the testator's contrary intent.

The history of the seal follows a similar path from nondefeasible to defeasible. Williston's description of the early use of the seal suggests it was a nondefeasible formality. No evidence of the parties' contrary intent would defeat its legal effect. In fact, "one whose seal was attached to an obligation was bound, even though the seal had been stolen and attached to the

${ }^{41}$ James Bradley Thayer, A Preliminary Treatise on Evidence at the Common Law 448-49 (1898).

${ }^{42}$ John Henry Wigmore. See 5 John Henry Wigmore, A Treatise on the Anglo-American Law of Evidence in Trials at Common Law, § 2463, 383 (2d ed. 1924) (hereinafter "Wigmore (2d ed.)"). 
instrument without his consent." ${ }^{43}$ Over time the effects became increasingly defeasible. Thus by the time of the Second Restatement, the drafters maintained that "[t]he adoption of a seal may be shown or negated by any relevant evidence as to the intention manifested by the promisor." ${ }^{\prime 4}$

Judicial construction can also transform ordinary boilerplate into a legal formality. ${ }^{45} \mathrm{~A}$ court's construction of a string of words can give them a legal meaning very different from their everyday content. For several centuries, the standardized language in a Lloyd's marine insurance policy used the following words to describe covered risks:

Touching the Adventures and Perils which we the Assurers are contented to bear and do take upon us in this Voyage, they are, of the Seas, Men-of-War, Fire, Enemies, Pirates, Rovers, Thieves, Jettisons, Letters of Mart and Counter-mart, Surprisals, Takings at Sea, Arrests, Restraints and Detainments of all Kings, Princes, and People, of what Nation, Condition or Quality soever, Barratry of the Master and Mariners, and of all other Perils, Losses and Misfortunes that have or shall come to the Hurt, Detriment, or Damage of the said Goods and Merchandises and Ship, \&c., or any Part thereof. ${ }^{46}$

In his 1914 treatise, Sir Douglas Owen observed of the clause:

It is an ancient and incoherent document, occasionally the subject of judicial remarks in the highest degree uncomplimentary. But nobody minds this or dreams of altering the ancient form, nor, one may imagine, is it ever likely to be altered. Insurance experts know-or very often know-exactly what it means, and with generations of legal interpretations hanging almost to every word, and almost certainly to every sentence, in it, it would be highly dangerous to tamper with it. ${ }^{47}$

${ }^{43} 1$ Williston (1st ed.) § 205, 412.

${ }^{44}$ Restatement (Second) Contracts $\S 98 \mathrm{cmt}$. a (1981). See also id. $\S 96 \mathrm{cmt}$. b (" $[\mathrm{A}]$ document which bears a seal does not establish its own authenticity. Evidence of extrinsic circumstances may be necessary to show that a promisor affixed or adopted a seal and that the document was delivered."); 1 Williston on Contracts $\S 2: 2$ n.11 (4th ed. 2016) (citing cases); Holmes, supra note 35, at 636-37 (1993) (discussing the modern requirement of a party's intent to deliver the sealed instrument).

${ }^{45}$ See Ayres, supra note 22, at 2082.

${ }^{46}$ I am grateful to Jim Oldham for bringing this example to my attention. See James C. Oldham, Insurance Litigation Involving the Zong and other British Slave Ships, 1780-1807, 28 J. Legal Hist. 299, 300 (2007).

${ }^{47}$ Sir Douglas Owen, Ocean Trade and Shipping 155 (1914). See also id. at 158 "If such a contract were to be drawn up for the first time to-day, it 
Such standard clauses are also legal formalities. When used by sophisticated parties, their legal meaning lies entirely in the rules of construction that determine their legal effect. Those rules of construction can be found in judicial opinions construing the clause to apply to various factual constellations. So long as the proper words are used, they do not require interpretation but only construction.

Ian Ayres suggests yet another way formalities might come into existence. In addition to construing language in the parties' contract, courts might recommend words future parties can use to avoid the default. Thus Ayres points out that although in Jacob \& Youngs v. Kent Justice Cardozo suggested parties might avoid the substantial performance rule through the use of "apt and certain words," Cardozo did not say what words would suffice to achieve that legal effect. Ayres sees this a shortcoming.

Jacob \& Youngs is a classic example of a court announcing a default but failing to specify the associated altering rules. . . . Judge Cardozo found that the parties' attempts to displace the substantial performance rule were insufficient, but he did not indicate what words would be sufficient. Particularly, when a court determines that a contractor's attempts to displace or preserve a default were insufficient to achieve the result advocated by the losing side in a dispute, courts should drop a footnote identifying what language would be sufficient or explaining why they are not providing such language. ${ }^{48}$

Had Cardozo dropped a footnote providing, in dicta, specific words parties might use to avoid the substantial performance rule, courts encountering that language in subsequent cases might, in their holdings, have construed the language to create a new legal formality.

Ayres would have judges take a more active role in the creation of formalities than they currently do. Under existing legal practices, contract formalities exist either by ancient custom, like the seal, by legislative fiat perhaps building on custom, such as the UCC rules for "F.O.B." and "as

would be put down as the work of a lunatic endowed with a private sense of humour.").

${ }^{48}$ Ayres, supra note 22 at 2056. See also id. at 2055 ("In deciding interpretation disputes, and in fact in deciding any contractual issue concerning defaults, judges should presumptively provide in their decisions contractual language that would allow future contractors to achieve the results desired by the losing party. Judges should strive to tell losing parties how they can alter future contracts to win next time.") 
is, ${ }^{49}$ or through the judicial construction of standard terms chosen by parties, as in the Lloyd's marine insurance policy. Ayres proposes a fourth source: judicial drafting of words sufficient to contract around the default. Whether this would be a good thing is debatable. Responding to Lisa Bernstein's studies of trade associations, David Charny expressed doubts:

As Bernstein reports, [trade association] tribunals frequently include in their opinions drafts of contract terms that should be incorporated into contracts to avoid future disputes. Note how this procedure lays the foundation for formalism in the next round: the trade association adjudicator can now insist that the dispute be resolved decisively by the presence or absence of a particular term, which, for the tribunal, has a built-in imprimatur and a preannounced meaning. In contrast, common law courts lack the institutional machinery for this prospective rulemaking: they are inexpert, they do not face contract cases from any specific industry often enough to mold practice, and they lack the means to communicate their decisions in a way that would reach the full range of transactors. ${ }^{50}$

Whether courts should take Ayres's advice and use their opinions to generate new formalities depends on empirical facts about judicial competence and party responsiveness - facts that we do not have much hard data about. ${ }^{51}$ Here I merely note judicial innovation as a possible fourth way.

The relationship between formalistic altering rules and the generic senses of "formalism" should be obvious. Legal formalities work by circumventing interpretation altogether. In order to determine the legal state of affairs, a third-party adjudicator need look only to the use of the formality, not at its meaning or the parties' intent. Formalistic altering rules can render appeal to anything other than the use vel non of the formality unnecessary. Accordingly, they call for a minimal evidentiary base and are largely context insensitive.

${ }^{49}$ Of course legislative fiat may involve putting a legal imprimatur on words already in use among responsive parties. Most formalities have histories. ${ }^{50}$ Charny, supra note 7 at 848.

${ }^{51}$ Though recent experience with judicial interpretations of pari passu clauses in sovereign debt contracts suggests even sophisticated parties are often not very responsive. In the immediate aftermath of judicial rulings on the legal meaning of the standard clause that went against the understanding of most lawyers in the field, those lawyers did not redraft their standard contracts to clarify the clauses' meaning. See Mitu Gulati \& Robert E. Scott, The Three and a Half Minute Transaction: Boilerplate and the Limits of Contract Design 45-72 (2013). 
Klass: Contract Exposition and Formalism

This is not to say extrinsic evidence cannot enter into the case. Except in the most extremely formalistic altering rules, use of a contract formality does not preclude the introduction of context evidence to show duress, fraud, mistake or another invalidating cause. Many Article Two provisions that establish formalities also provide that the parties' might agree to a different legal meaning-that they might alter the formalistic altering rule. ${ }^{52}$ And defeasible formalities create only a presumption of legal change, which might be defeated by evidence of the parties' contrary intent. But in all these cases the evidence is relevant to show only that the formality has malfunctioned, has been redesigned, or is rebutted. In the first instance, formalities support, and even demand, a high degree of formalism.

\subsection{Interpretive formalism}

Contract law has its share of formalities. But they hardly dominate. And they are almost always paired with interpretive altering rules. Words or actions with the right meaning usually also suffice. Consider again the Code's rule for the implied warranty of merchantability. Section 2-316(3)(a), provides that a seller can disclaim all implied warranties by using the formalities "as is" or "with all faults." But section 2-316(2) provides a separate way to alter the default warranty: "to exclude or modify the implied warranty of merchantability or any part of it [under this section] the language must mention merchantability and in case of a writing must be conspicuous." This rule has formal components. The language must mention of "merchantability" and, if in a writing, be conspicuousness. But it does not identify magic words sufficient to disclaim the implied warranty. Instead the seller must make a statement with the right meaning-one that says that the seller does not warrant merchantability. The formalistic "as is" altering rule is paired with a mixed interpretive one. Although contract law sometimes provides that the use of a formality is sufficient to effect a legal change, it is rarely if ever specifies that its use is necessary to effect the change.

Moreover, many interpretive contract altering rules have no formalistic counterparts. There are no formalities associated with important acts such as making an offer, accepting an offer, expressly warranting the quality of goods, liquidating damages, waiving a condition, or committing anticipatory breach. These legal changes can occur only when one or both parties say or do something with the right meaning. The altering rules are interpretive only.

This section is about interpretive altering rules. I have already identified one sense in which an interpretive altering rule might be said to be formal: a mixed interpretive rule includes one or more formal

${ }^{52}$ See, e.g., UCC $\S \S 2-319$ (describing the meaning of "F.O.B" and "F.A.S." "unless otherwise agreed"). 
components, such as writing or signature requirements. I now identify two additional and in my view more significant senses, both of which figure into what are commonly called plain meaning rules. They correspond to what Wigmore called "two great divisions of the process" of interpretation: "The first question must always be, What is the standard of interpretation? The second question is, In what sources is the tenor of that standard to be ascertained?"53 The first question is what type of meaning interpretation seeks to identify; the second what evidence the interpreter may use when determining it. After discussing each, I describe how plain meaning rules include elements of both.

\subsubsection{Literal meaning formalism}

An interpretive altering rule requires that one or both parties say or do something with the right meaning. But the word "meaning" itself has multiple meanings. People interpret the meanings of novels, poems, metaphors, dreams, a moment of silence, a slip of the tongue, a glance across the room, a fall in the stock market, tea leaves in the bottom of a cup, and of course the words and actions of parties who might or might not have entered into a contract. Although these interpretive activities share family resemblances, they involve very different types of inquiries, which seek out very different sorts of meanings. An interpretive altering rule must identify the type of meaning that is legally relevant.

Even within contract interpretation one finds a variety of legally relevant meanings of "meaning." Contract law does not have a single, master altering rule, but contains a collection of rules, many tailored to the type of transaction, to who the parties are, to the type of act, and to the legal question at issue. Different altering rules within contract law call for different types of interpretation of different sorts of meaning. ${ }^{54}$ Here I focus on three central distinctions: between communicative content and propositional attitudes; between literal meaning and use meaning; and between common literal meaning and local literal meaning.

${ }^{53} 5$ Wigmore (2d ed.) § 2458, 367.

${ }^{54}$ Lawrence Solum has argued that "the determination of communicative content proceeds differently in different legal contexts," but focuses primarily on differences between broad areas of law-constitutional law, statutory law, the application of judicial precedent, contract law, etc. Lawrence B. Solum, Communicative Content and Legal Content, 89 Notre Dame L. Rev. 479, 482 (2013). As distinguished from the intermural differences that Solum emphasizes, I am pointing to intramural differences within the law of contract. 
Klass: Contract Exposition and Formalism

\subsubsection{Communicative content and propositional attitudes}

Many contract altering rules require an agreement between or among the parties. Examples include the rules for formation, modification, substituted performance, and accord and satisfaction. Other contract altering rules provide that a unilateral act can suffice to change the parties' legal relationship. These include the rules for offer, acceptance, waiver of a condition, repudiation, and demands for adequate assurance. To keep things simple, this section begins by focusing on agreement-based altering rules. But its conclusions apply equally to altering rules that identify unilateral acts as sufficient to effect a legal change.

"Agreement" is yet another ambiguous word. In our everyday talk, we sometimes use it to refer to the words people use to reach an accord, as in, "The parties each signed the agreement." At other times we use it to refer to the mental states of being in accord, as in, "Two men, who pull the oars of a boat, do it by agreement or convention, tho' they have never given promises to each other. ${ }^{\prime \prime 55}$ Agreements in the former sense, which I will call acts of agreement, usually take the form of communicative acts, such as an offer followed by an acceptance. Agreements in the latter sense, which I will call actual agreements, are sets of interlocking beliefs and intentions, or what philosophers call "propositional attitudes," ${ }^{156}$ that two or more persons have about what each shall do. ${ }^{57}$ Acts of agreement are communications and have communicative content; actual agreements are states of mind and involve propositional attitudes.

The two meanings of "agreement" are closely related. People typically arrive at an actual agreement by performing acts of agreement. They use words to achieve the shared intentions and beliefs that put them in agreement: "Shall we go?" "Yes, Let's go." "Good. We're in agreement." And for third-party adjudicators, parties' acts of agreement are usually the best evidence both of whether they have reached an actual agreement and of its terms.

But the two types of agreement are not coextensive. An actual agreement can sometimes exist, for example, even when one side does not express her agreement to it. Thus courts have held that when a seller has a history of fulfilling a buyer's orders without further communication, an order from the buyer together with the seller's silence might cause both to reasonably understand that the seller has accepted the order and shipment

${ }^{55}$ David Hume, Of Morals, in A Treatise on Human Nature 291, 315 (David Fate Norton \& Mary J. Norton eds., Oxford Univ. Press 2000) (1739-1740). ${ }^{56}$ A propositional attitude is, roughly speaking, a mental state that can be expressed with a verb that takes a that-clause, such as "believes that...", "intends that...", "wishes that..."

${ }^{57}$ For more on the relationship between agreements and the parties' intentions, see Michael E. Bratman, Shared Cooperative Activity, in Faces of Intention: Selected Essays on Intention and Agency 93 (1999). 
is forthcoming. ${ }^{58}$ The parties are in actual agreement, though one of them has not performed an act of agreement. The content of the parties' actual agreement can also extend beyond their acts of agreement. This can happen, for example, when the parties' shared understanding of their agreement comes from past dealings between them, from common industry practices, and as time passes from the course of performance of the agreement itself. Thus courts have also recognized that a seller and buyer who have an established practice of setting the price according to the seller's profits on resale might, in their act of agreement to a new transaction, say nothing about the price, yet be in agreement on how the buyer will be paid. ${ }^{59}$ Here the actual agreement is richer than what is said in the act of agreement.

The distinction between acts of agreement and actual agreements corresponds to two types of interpretation one finds in contract cases: interpretation of what the parties said and interpretation of what the parties believed or intended. ${ }^{60}$ The first aims to discern the communicative content of the parties' words and action; the second to discern the parties' legally relevant propositional attitudes-their beliefs and intentions. The two inquiries are related. What the parties intend and believe-whether they are, for example, in actual agreement-turns in part on the communicative content of their words and actions. And, as I discuss below, interpreting the meaning of what the parties have said sometimes involves asking what they intended to say. But the inquiries pose different questions, and the answers to those questions involve different types of reasoning and evidence.

An altering rule might look either to communicative content of what the parties say or to the parties' beliefs and intentions. Again Wigmore anticipates the point: "The distinction between 'intention' and 'meaning' is vital," and "[t] he rules for the two things may be different." ${ }^{161}$ As an example, consider the very different rules that apply to two types of

${ }^{58}$ See Restatement (Second) of Contracts $\S 69$ ill. 5 (1981) (based on Ammons v. Wilson, 176 Miss. 645 (1936)).

${ }^{59}$ See Restatement (Second) of Contracts $§ 223$ ill. 1 (1981) (based on California Lettuce Growers, Inc. v. Union Sugar Co., 45 Cal.2d 474, 289 P.2d 785 (1955)).

${ }^{60}$ For more on this distinction, see the discussion of "manifest intent" and "express statement" opt-out rules in Klass, Intent to Contract, supra note 22. ${ }^{61} 5$ Wigmore ( $2 \mathrm{~d}$ ed.) $\S 2459,369,370$. Wigmore's distinction is not identical to the one I will be drawing, as Wigmore is especially interested in the mental state of intending the act, whereas I am interested in parties' intentions and understandings more generally. Thus for Wigmore, "[t]he contrast is between the Will, or volition to utter, which, as the intuitive element of an act, makes a person responsible for a particular utterance of his, and that Sense or meaning which involves the fixed association between the uttered word and some external object." Id. at 369-70. 
unilateral acts: waiver of a condition and revival of a debt discharged in bankruptcy. ${ }^{62}$

Although the Second Restatement describes a waiver as a "promise to perform . . . in spite of the nonoccurrence of the condition," ${ }^{\prime 3}$ in practice all a party must do to waive a condition is to manifest an intention to perform despite the condition's nonoccurrence. Thus the current edition of Williston observes that a waiver can be found based solely on "a party's conduct inconsistent with the assertion of the right to the performance allegedly waived, or by conduct that indicates that strict compliance with the contract will not be required." ${ }^{64}$ Whether a party has waived a condition turns not, or not only, on what she said, but on what she appeared to intend with respect to her own performance. In Tenneco $v$. Enterprise Products, for example, the Texas Supreme Court considered whether a co-owner of a natural gas processing plant violated its contractual obligations to the other owners by transferring its interest to a subsidiary and then failing to provide contractually required raw materials. ${ }^{65}$ The court held that the nonbreaching owners' failure to complain about the noncompliance for over three years, together with their apparent acceptance of the subsidiary as a co-owner, effectively waived their rights to pursue remedies for the breach. "Silence or inaction, for so long a period as to show an intention to yield the known right, is . . . enough to prove waiver" of a contractual right. ${ }^{66}$ The inquiry here did not involve the meaning of what the other owners said, but rather the reasonable interpretation of their actual intentions with respect to enforcing their contractual rights. The rule is not about communicative content, but the waiving party's apparent beliefs and intentions.

${ }^{62}$ Another excellent example of the difference can be found in the different rules for preliminary agreements adopted by Judge Leval in Teachers Insurance and Annuity Association v. Tribune Co., 670 F.Supp. 491 (S.D.N.Y. 1987), and Judge Easterbrook in Empro Manufacturing Co., Inc v. Ball-Co Manufacturing, Inc., 870 F.2d 423 (8th Cir. 1989). Leval adopts what I am calling an actual agreement rule, whereas Easterbrook would look exclusively to the parties' acts of agreements. See Klass, Intent to Contract, supra note 22 at 1480-88 (discussing Teachers Insurance and Empro).

${ }^{63}$ Restatement (Second) of Contracts $\S 84(1)$ (1981) (emphasis added). ${ }^{64} 13$ Williston on Contracts $\S 39: 30$ (4th ed.). See also Restatement (Second) of Contracts $\S 84(1) \mathrm{cmt}$. e (1981) ("It is immaterial how the promisor manifests his intention to fulfill the prior duty without the performance of the condition. Words of promise or waiver, though often used, are unnecessary; in many situations non-verbal conduct is enough.").

${ }^{65}$ Tenneco Inc. v. Enter. Products Co., 925 S.W.2d 640 (Tex. 1996).

${ }^{66} / d .643$. 
The old rule for reviving a debt discharged in bankruptcy, on the contrary, required that the debtor expressly promise that she would pay the debt. A debt discharged in bankruptcy could be revived without consideration only by the debtor's "express promise to pay all or part" of it. ${ }^{67}$ Thus in Service Finance Company of Baton Rouge v. Diagle, a Louisiana appellate court held that three payments on a debt subsequent to its discharge, plus the debtor's statement "that he was going to continue to pay this account," were insufficient to revive a discharged debt. ${ }^{68}$

In order to revive a liability on a debt discharged in bankruptcy or to create a new enforceable obligation, there must be an express promise to pay the specific debt, made to the creditor or his agent, and while no particular form of language is necessary, to constitute such a new promise there must be a clear, distinct, and unequivocal recognition and renewal of the debt as a binding obligation, anything short thereof being insufficient, as, for example, the mere acknowledgment of the discharged debt, or the expression of hope, desire, expectation, or intention to pay or revive the same. ${ }^{69}$

As I will explain shortly, this is a literal meaning altering rule. It requires courts to look to the literal meaning of the debtor's words. The present point, however, is simply that it looks to the meaning of the debtor's words, not to the debtor's apparent intentions.

\subsubsection{Literal meaning and use meaning}

A second important distinction lies is among types of communicative content. This is the distinction between a speech act's literal meaning and its use meaning, or what philosophers and linguists sometimes call "semantic meaning" and "pragmatic meaning." Describing each requires a brief detour through the philosophy of language.

As I will use the terms, the literal meaning, or semantic meaning, of a word or string of words is its conventional meaning in some language $\mathrm{L}$. The conventional meaning of a sentence $S$ is, roughly, determined by (1) the conventional meaning in some language $L$ of $S^{\prime}$ s component parts, (2) the rules of syntax in L, and sometimes (3) conventional rules for how the context of S's use can figure into its meaning on the occasion of its use. The first two aspects of literal meaning-dictionary definitions of words and the

${ }^{67}$ See Restatement (Second) of Contracts $\S 83$ (1981). For changes introduced by the 1978 Bankruptcy Reform Act and subsequent legislation, see 4 Williston on Contracts § 8:21 (4th ed. 2016).

${ }^{68}$ Serv. Fin. Co. of Baton Rouge v. Daigle, 342 So. 2d 1192, 1193 (La. Ct. App. 1977).

${ }^{69}$ Id. (quoting Irwin v. Hunnewell, 207 La. 422, 435, 21 So.2d 485, 489

(1945)). 
rules of syntax-are familiar. The third element is illustrated by indexicals such as the word "here." The literal meaning of the sentence "It is cold in here," for example, turns on the rule that "here" refers to the speaker's location.

Paul Grice suggests an example that illustrates several important aspects of literal meaning and also the difference between literal and use meaning. Consider an utterance of the following sentence:

S If I shall then be helping the grass grow, I shall have no time for reading. ${ }^{70}$

There are several things to notice about the literal meaning of $\mathrm{S}$ on one or another occasion of its use.

First, although Grice does no mention it, the indexical "I" in S illustrates how literal meaning of a word can depend on the context of its use. What "I" refers to in any given use of $S$ depends on the identity of the speaker. There is an aspect of literal meaning as I have defined it, as there is a purely conventional rule for determining the reference of " $\mathrm{I}$ ": it refers to the speaker.

Second, Grice puckishly observes that S's literal meaning in contemporary English is ambiguous, as "grass" refers both to the stuff of which lawns are composed and to marijuana. Standing alone $\mathrm{S}$ has two possible literal meanings:

LM1 If I shall then be assisting the kind of thing of which lawns are composed to mature, I shall have no time for reading,

and

LM2 If I shall then be assisting the marijuana to mature, I shall have no time for reading. ${ }^{71}$

Words can have more than one literal meaning. They can be ambiguous.

Third, although this was not Grice's point, the example also illustrates that words have literal meanings only in one or another language or dialect. In 1969, when Grice' article was published, S was ambiguous in the way he identified. The conventional meanings of "grass" included both the stuff of which laws are composed and marijuana. But one can easily imagine English dialects-say before the widespread familiarity with marijuana-in which "grass" means only the stuff of which lawns are

${ }^{70}$ Paul Grice, Utterers Meaning and Intentions, 78 Phil. Rev. 147 (1969), reprinted in Paul Grice, Studies in the Way of Words 86, 88 (1989).

${ }^{71}$ Id. at 89. 
composed, and in which S has only one literal meaning. ${ }^{72}$ To identify literal meaning, you need to first identify the relevant language.

Fourth, on any given occasion, a speaker or writer might use an ambiguous sentence like $S$ to express one or another of its literal meanings. A busy greenskeeper who utters $S$ in response to an invitation to join a book club is likely using it to communicate LM1. A busy grow house employee who utters $S$ in response to the same invitation is likely using it to communicate LM2. In each case, the use meaning corresponds to one of $S^{\prime} \mathrm{s}$ literal meanings. In order to determine which literal meaning is meant_-in order to disambiguate $\mathrm{S}$-one must sometimes look to the circumstances of its use.

Grice further observes that a speaker might also use $S$ to communicate something other than its literal meaning. Suppose Gertrude Stein writes $S$ in an essay on the banality of journalism. In this context, it might make sense to interpret her words as meaning:

UM If I am then dead I shall not care what is going on in the world..$^{73}$

Assuming that "helping the grass grow" is not an established idiom for being deceased, Stein's metaphorical meaning on this occasion does not correspond to any of S's literal meanings, although it depends on LM1. Stein is using $S$ to say something entirely different. Her use meaning departs from the sentence's literal meanings.

Here we might pause to distinguish three very different functions that the context of $S^{\prime}$ 's use serves in these examples: (1) to determine the referent of "I"; (2) to identify which of two literal meanings makes sense in that context; and (3) to show that a speaker meant something other than the literal meaning of her words. The first depends entirely on the conventions that govern the meaning of "l." The second brings us closer to the interpretation of use meaning, but involves merely the choice between literal meanings. The third requires going beyond literal meaning altogether.

If literal meaning is conventional meaning in some language, how should we describe use meaning? Theorists have suggested various

${ }^{72}$ As recently as 1943 Time Magazine felt the need to explain to its readers that "grass" is sometimes used to refer to marijuana. The Weed, Time Magazine 54 (July 19, 1943) ("Marijuana may be called muggles, mooter, Mary Warner, Mary Jane, Indian hay, loco weed, love weed, bambalacha, mohlasky, mu, moocah, grass, tea or blue sage."). The Oxford English Dictionary does not identify any earlier print evidence of this meaning. ${ }^{73}$ Compare Grice, supra note 70 at 89-90. 
accounts. ${ }^{74}$ Here I rely on Grice's theory, which is both foundational and relatively accessible. ${ }^{75}$

Grice argues that an utterance's use meaning, or its pragmatic meaning, depends on the communicative intentions it is reasonable to attribute to the speaker in the circumstances. Kent Bach and Robert Harnish, who follow Grice in this respect, describe the interpretation of use meaning as follows:

The hearer ... seeks to identify the speaker's intention in making the utterance. In effect the hearer seeks to explain the fact that the speaker said what he said, in the way he said it. Because the intention is communicative, the hearer's task of identifying it is driven partly by the assumption that the speaker intends him to do this. The speaker succeeds in communicating if the hearer identifies his intention in this way, for communicative intentions are intentions whose "fulfillment consists in their recognition." Pragmatics is concerned with whatever information is relevant, over and above the linguistic properties of a sentence, to understanding its utterance. $^{76}$

${ }^{74}$ Robyn Carston identifies five separate ways scholars have tried to draw the distinction between semantic meaning and pragmatic meaning. Linguistic Communication and the Semantics/Pragmatics Distinction, 165 Synthese 321, __ (2008). See also Börjesson, Kristin, The SemanticsPragmatics Controversy (2014); Kent Bach, The Semantics/Pragmatic Distinction: What It Is and Why It Matters, Linguistische Berichte, Sonderheft 8, 33 (1997).

${ }^{75}$ See especially H.P. Grice, Logic and Conversation, in The Logic Of Grammar 64 (Donald Davidson \& Gilbert Harman eds., 1975), reprinted in Paul Grice, Studies in the Way of Words 22 (1989).

I believe that a more complete and perspicuous account of pragmatic meaning can be found in Robert Brandom's theory of discursive commitments. Robert Brandom, Making it Explicit: Reasoning, Representing and Discursive Commitment (1998). Brandom's account has the advantage of starting not from an unanalyzed concept of intention, but from precisely defined, if unfamiliar, concepts of social practices such as deonitic status and scorekeeping. It has the disadvantage of being highly technical and relatively inaccessible. For a more approachable account that builds on Bradom's work, and ties use meaning directly to the legally salient category of normative powers, see Rebecca Kukla and Mark Lance, 'Yo!' and 'Lo!': The Pragmatic Topography of the Space of Reasons (2009).

${ }^{76}$ Kent Bach \& Robert M. Harnish, Linguistic Communication and Speech Acts 15 (1979). 
Grice argues that we attribute communicative intentions on the assumption that speakers seek to comply with a Cooperative Principle: "Make your conversational contribution such as is required at the stage at which it occurs, by the accepted purpose or direction of the talk exchange in which you are engaged." 77 Thus in the context of a greenskeeper's conversation about whether she might join a book club, it is reasonable to interpret her utterance of $\mathrm{S}$ as expressing LM1 rather than LM2. In an essay by Gertrude Stein about journalism, in which neither lawns nor marijuana is at issue, it would be more reasonable to interpret her as intending the metaphorical meaning UM. Whereas a sentence's literal meaning in a language is conventionally defined, the use meaning of an utterance of it depends on the communicative intentions it is reasonable to attribute to the speaker. Because people can express and exhibit such intentions in nonconventional ways, use meaning does not always correspond to literal meaning.

Contracts casebooks are filled with examples of the distinction between literal and use meaning. Although contracting parties rarely speak in metaphor, they often speak elliptically, with malapropisms, ironically or with hyperbole. In Embry v. Hargadine, McKittrick Dry Goods Co., for example, the question was the legal effect of a company president's statement to an employee, who was threatening to quit if not given a new contract, "Go ahead, you're all right; get your men out and don't let that worry you." ${ }^{\prime 8}$ The words' literal meaning was that the employee should get back to work and not worry about the contract. The court found, however, that in context "no reasonable man would construe that answer to Embry's demand that he be employed for another year, otherwise than as an assent to the demand." ${ }^{79}$ The use meaning of the manager's words departed from their literal meaning. The interpretation of use meaning can also be necessary to identify humor, irony or puffery. Leonard v. Pepsico, considered a television advertisement showing various items that could be purchased with promotional "Pepsi Points," including a Harrier Jet with the words, "HARRIER FIGHTER 7,000,000 PEPSI POINTS." ${ }^{80}$ Here the court held that in the context of the advertisement, which employed "zany humor," "no reasonable, objective person would have understood the commercial to be an offer." ${ }^{11}$ Again, the words' use meaning departed from their literal meaning.

Literal meaning rules are rare in contract law, with plain meaning rules_discussed below-being more common. But they do exist. The old rule for reviving a debt discharged in bankruptcy, which required "an

${ }^{77}$ Grice, supra note 75 at 26.

78127 Mo. App. 383, 105 S.W. 777, 777 (1907).

${ }^{79}$ Id. at 779.

${ }^{80} 88$ F. Supp. 2d 116, 119 (S.D.N.Y. 1999), aff'd, 210 F.3d 88 (2d Cir. 2000).

${ }^{81}$ Id. at 131. 
express promise to pay," is an example. So too is Williston's Model Written Obligation Act: "A written release or promise . . . shall not be invalid or unenforceable for lack of consideration, if the writing also contains an additional express statement, in any form of language, that the signer intends to be legally bound." ${ }^{22}$ Such express statement requirements tell adjudicators to look to the literal meaning of the parties' words.

So far I have identified two differences among the types of interpretation that figure into contract cases. The first is between interpretation that seeks out the meaning of acts of agreement and interpretation that seeks out the beliefs and intentions that constitute actual agreements, or more generally, the distinction between communicative content and propositional attitudes. The second is within the interpretation of communicative content, and is the difference between interpreting the literal meaning of the parties' words and actions and interpreting their use meaning, or between what philosophers call semantic and pragmatic meaning. Neither of these distinctions should be confused with lawyerly distinction between subjective and objective meaning. In contracts jurisprudence, subjective meaning refers to one or more party's individual, perhaps idiosyncratic, and probably undisclosed understandings of the parties' words and actions, whereas objective meaning refers to those words' or actions' publically available meaning, or what a reasonable person standing in a party's shoes would understand them to mean. Literal meaning is always objective in this sense. The conventional meaning of words in some language is a fact about the social world. Both the parties' actual agreement and the use meaning of their words and actions, in distinction, can be understood either subjectively or objectively. ${ }^{83}$ Although the parties' actual beliefs and intentions are subjective facts, the beliefs and intentions it is reasonable to attribute them in the circumstances is an objective one. Altering rules that condition legal change on the parties' actual agreement or the use meaning of their words and actions can therefore be as objective as those that condition legal change on their literal meaning. This was the holding in Embry, discussed above: "[T]hough McKittrick may not have intended to employ Embry by what transpired between them ...., yet if what McKittrick said would have been taken by a

${ }^{82}$ Model Written Obligations Act $\S 1$, in Handbook of the National Conference of Commissioners on Uniform State Laws and Proceedings of the Thirty-Fifth Annual Meeting 584 (1925).

${ }^{83}$ In his contracts opinions, Judge Easterbrook sometimes wrongly suggests that the objective theory entails a literal meaning approach. See, e.g., Empro Manufacturing Co., Inc v. Ball-Co Manufacturing, Inc., 870 F.2d 423, 424-25 (8th Cir. 1989); Skycom Corp. v. Telstar Corp., 813 F.2d 810, 814-17 (7th Cir.1987). 
reasonable man to be an employment, and Embry so understood it, it constituted a valid contract of employment." ${ }^{84}$

The potential relevance of pragmatic meaning and the parties' beliefs and intentions to the exposition of contractual agreements distinguishes contract interpretation from the interpretation of public laws. Many of the reasons for construing constitutions, statutes, regulations, judicial opinions and other expressions of public law according to their semantic meanings do not apply to written contracts. First, public laws, unlike most contracts, are addressed to the public at large and to persons far in the future, for whom semantic meaning is the more effective method of communication. ${ }^{85}$ Many contractual agreements, on the contrary, are communications between two parties and take place against a shared background understanding. Second, there exist structural-institutional reasons for focusing on a statute's semantic meaning that do not apply in the construction of contractual agreements. Some have argued, for example "that a restrained use of legislative history and focus on the text is necessary to prevent judicial usurpation of legislative power." ${ }^{\prime 86}$ Although it sometimes makes sense to think of contracts between sophisticated parties as a form of private legislation, contracts do not raise the same separation-of-powers issues. Third, contract law takes account of interests that have no analog in the enforcement of public laws. These include both the parties' autonomy interest in controlling their legal relationship and the social interest in having the parties' legal obligations track their moral ones. A contracting party whose words are legally interpreted in a way neither party anticipated given the context in which she was speaking suffers a type of wrong that a legislator cannot suffer.

None of this is to say that use meaning and the parties' actual beliefs and intentions should always control. But the arguments for attending to use meaning and the parties' actual agreement are different and potentially more compelling in contract than elsewhere.

\subsubsection{Common meaning vs. local meaning}

The third and final important distinction identifies a difference among literal meanings. The literal meaning of a speech act is its conventional meaning in some language. As the example of "grass" shows, words often have different conventional meanings in different languages or

${ }^{84} 105$ S.W. at 779.

${ }^{85}$ See William N. Eskridge, Jr., The New Textualism, 37 UCLA L. Rev. 621, 667 (1990) ("By focusing on the literal meaning a statute would have for the ordinary, reasonable reader, the new textualism has the intuitive appeal of looking at the most concrete evidence of legislative expectations and at the material most accessible to the citizenry. The statutory text is what one thinks of when someone asks what the 'law' requires.").

${ }^{86} / d$. at 648. 
dialects. A completely articulated literal meaning altering rule therefore specifies not only that the conventional meaning of the parties' words and actions controls, but also what language the interpreter should use to determine their conventional meaning.

Contract law has long recognized that parties sometimes speak in languages that that diverge from dictionary English. Thus Wigmore distinguishes between "the standard of the community, or popular standard, meaning the common and normal sense of words; [and] the local standard, including the special usages of a religious sect, a body of traders, an alien population, or a local dialect." ${ }^{87}$ I will call literal meaning in ordinary dictionary English common meaning and literal meaning in more localized dialects local meaning. In the Uniform Commercial Code, the idea of local meaning falls under heading of usage of trade. "The language used is to be interpreted as meaning what it may fairly be expected to mean to parties involved in the particular commercial transaction in a given locality or in a given vocation of trade. ${ }^{\prime 88}$

Alan Schwartz and Robert Scott have suggested that there are only two possible answers to the which-language question: "majority talk" or "the parties' private language." ${ }^{89}$ Wigmore's more nuanced position shows

${ }^{87} 5$ Wigmore ( 2 d ed.) $\S 2460,372$ (emphasis in the original). Williston quotes the same from the first edition of Wigmore, 2 Williston (1st ed.) $\S$ 604,1162 . But whereas Wigmore understands the local standard as a form of, in my idiom, literal meaning, see 5 Wigmore ( 2 d ed.) $\S 2458,367$, Williston tends to run it together with use meaning. Thus Williston describes the "local standard" as "the natural meaning of the writing to the parties of the kind who contracted at the time and place where the contract was made, and with such circumstances as surrounded its making." 2 Williston (1st ed.) § 607, 1167 (emphasis added).

Wigmore identifies two additional categories of meaning: "the mutual standard, covering those meanings which are peculiar to both or all the parties to a transaction, but shared in common by them; and the individual standard of one party to an act, as different from that of the other party or parties, if any." Id. These would appear to be forms of use meaning, though Wigmore did not have the conceptual tools to identify them as such.

${ }^{88}$ U.C.C. 1-303 cmt. 3. The Code's definition of "usage of trade" includes much more than local literal meanings. "A 'usage of trade' is any practice or method of dealing having such regularity of observance in a place, vocation, or trade as to justify an expectation that it will be observed with respect to the transaction in question." Id. § 1-303(c). Under this definition, usages of trade include not only linguistic conventions, but also transactional ones.

${ }^{89}$ Alan Schwartz \& Robert E. Scott, Contract Theory and the Limits of Contract Law, 113 Yale L.J. 541, 584 (2003) ("The issue is whether, if the 
that the suggestion is wrong. Literal meaning altering rules can specify languages that are more or less local, both of which are to be distinguished from altering rules that specify use meaning-which appears to be what Schwartz and Scott mean by "the parties' private language." Williston, in formulating his plain meaning rule for written agreements, argued that "[t]he local standard is preferable to the normal [i.e., common] standard."

[A] reasonable degree of certainty is attained if words are construed according to a standard not peculiar to the parties, but customary among persons of their kind under the existing circumstances. The certainty obtained by enforcing always the normal standard would be but little greater, and would be obtained at the expense of a rigidity which would frequently do violence to the actual intention of the parties. That the local standard would be applied unless at any rate under the normal standard the words were extremely clear seems to have been early settled. Even though the local standard led to a construction opposed to the literal meaning of the language this was true..$^{90}$

In the same section, however, Williston recognizes that "in case of deeds of conveyance, or of negotiable instruments, which are relied upon not simply by the parties to them, but by others, the normal rather than the local standard may be defensible." ${ }^{\prime 11}$ Whether a literal meaning rule should use a common or a local standard cannot be decided a priori. It is a design choice that should be made on the basis of the legal goals and salient empirical facts. Williston again: "The standard of interpretation adopted by the law depends on the character of the contract under consideration." ${ }^{\prime 2}$

These three distinctions suggest the following classification of possible legally relevant meanings of "meaning" in contract cases:

contract is silent on the matter, a court should take the parties to have written in majority talk. The alternative judicial assumption would hold that, in case of a dispute, the parties prefer to have the opportunity to introduce extrinsic evidence that relevant parts of the contract were written in the parties' private language."). By "majority talk," Schwartz and Scott mean a rule "that restricts the court to the interpretive base $\mathrm{B}_{\min \prime}$ id. at 585, which they define as "the parties' contract, a narrative concerning whether the parties performed the obligations that the contract appears to require, a standard English language dictionary, and the interpreter's experience and understanding of the world," id. at 572.

902 Williston (1st ed) $\S 608,1171-72$.

${ }^{91}$ Id. at 1172 .

${ }^{92}$ Id., § 604, 1162. 


\section{Figure 2}

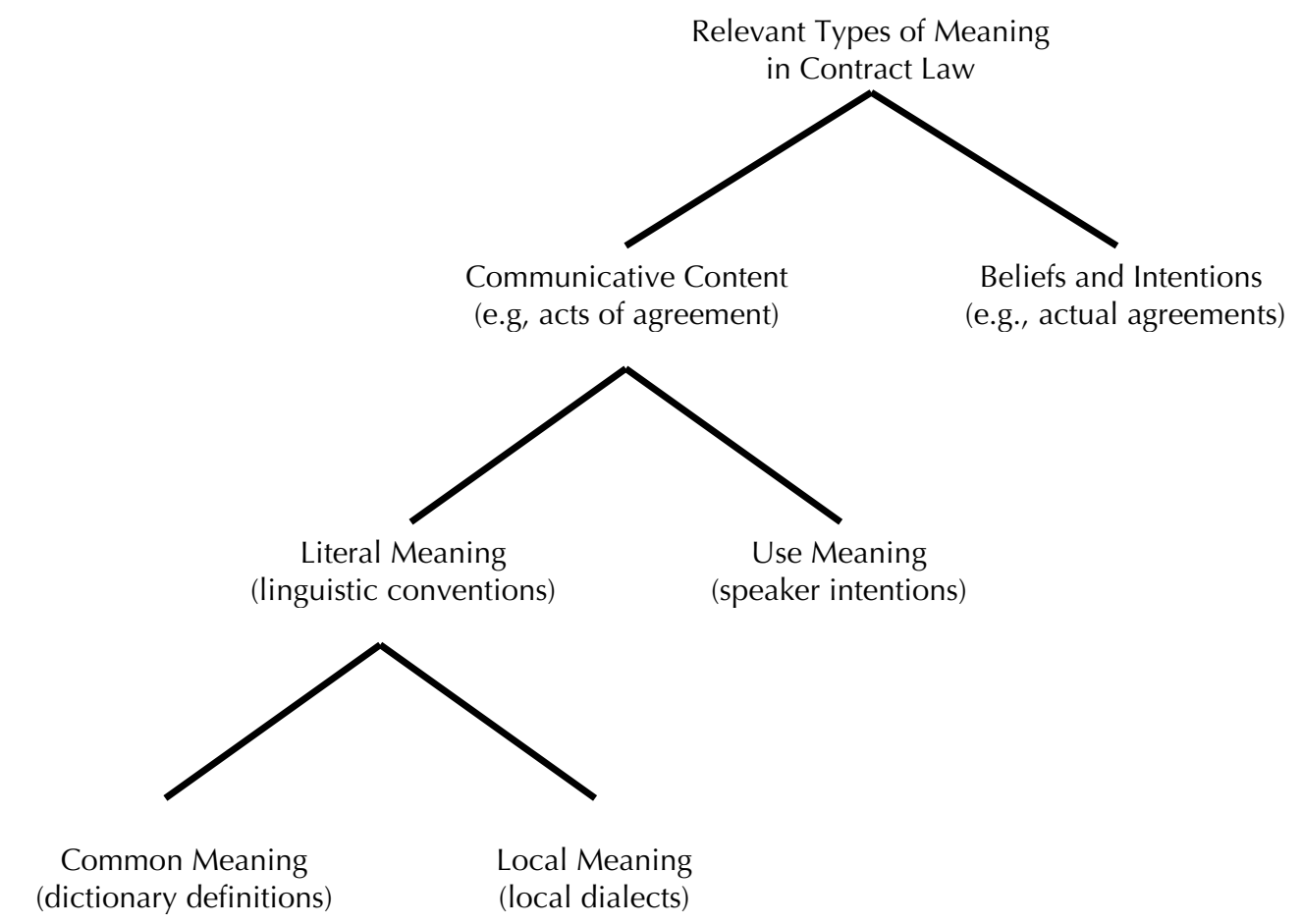

The further the desired outcome of interpretation is to the left on the tree, the less that meaning will vary across contexts and the less context evidence will be required to determine what it is. In other words, interpretive altering rules that condition legal outcomes on meanings to the left can be said to be more formalist than are rules that condition legal outcomes on meanings to the right. These distinctions are not exhaustive. We might further complicate it by adding the distinction between subjective and objective meanings, as well as the role that purpose plays in contract exposition. But this basic classification corresponds to significant fault lines among legally relevant types of meaning.

Before moving on to evidentiary rules, it is worth taking a few paragraphs to think about the relationship between literal meaning altering rules and legal formalities.

First, it is a mistake to run the two together. Literal-meaning altering rules condition legal change on the conventional meaning of the parties' words. Formalistic altering rules condition legal change on the performance of an act with the right formal qualities, which might include saying specific words. Whereas literal meaning rules require interpretation, formalities render it unnecessary.

Second, literal meaning and formalistic altering rules stand in a complex relation to one another. On the one hand, the application of a 
literal-meaning rule might generate a new legal formality. U.S. courts tend to treat the literal meaning of contractual agreements as a question of law, with the result that one court's interpretation of a clause in one agreement will often be taken as binding by subsequent courts interpreting the same language in another. A literal-meaning altering rule together with principles of stare decisis can thereby create a boilerplate formality where none existed before. On the other hand, the legal meaning of a formality might be, or might come to be, at odds with the words' literal meaning. Recall the Lloyd's insurance policy quoted above. Michele Boardman observes the same phenomenon in contemporary insurance contracts. Their standard clauses, she argues, are best understood as "a private conversation between drafters and the courts," one that consumers who rely on the written contract's literal meaning are likely to misunderstand..$^{93}$ Through the accretion of judicial construction, boilerplate can acquire a legal meaning that bears little resemblance to its literal meaning in ordinary English. Although literal meaning altering rules can produce legal formalities, formalistic altering rules can attach legal consequences to words that are at odds with their literal meaning.

Finally, literal meaning and formalistic altering rules support different degrees of formalism. The output of each depends less on context than does the interpretation of use meaning or of the parties' actual beliefs and intentions. But unlike some formalistic altering rules, literal meaning rules never render context evidence irrelevant. Although words' conventional meaning can be demonstrated without looking to their use meaning on a given occasion, how parties conversant in the relevant language in fact understood those words is evidence of their conventional meaning in it. If you do not know the language, evidence of how parties understood words in it can tell you something about those words' conventional meaning. Local literal meaning altering rules often call for extratextual evidence of local usage. And context evidence can help to resolve ambiguities in literal meaning, as illustrated by the multiple meanings of "grass" in S above. In short, whereas a formality can render context evidence irrelevant, a literal meaning rule renders it only less relevant as compared to a use meaning rule or actual agreement rule.

\subsubsection{Evidentiary formalism}

The second aspect of interpretive formalism involves not the type of meaning legal interpreters are instructed to seek, but the evidence they are permitted use to identify one or another meaning — what Wigmore calls the "sources" of interpretation.

${ }^{93}$ Michelle E. Boardman, Contra Proferentem: The Allure of Ambiguous Boilerplate, 104 Mich. L. Rev. 1105, 1105 (2006). 
One can think of a rule of interpretation as a function that maps a domain of interpretive inputs onto a range of interpretive outputs. ${ }^{94}$ The inputs always include the direct object of interpretation: the text, spoken words, gesture, or other act or omission whose meaning is at issue. The inputs also always include the interpreter's exegetic abilities and background knowledge of the world. Depending on the goal of interpretation-the type of meaning sought—and governing legal rules, interpretive inputs might additionally include dictionary definitions and rules of grammar, information about who the parties are and the commercial setting of the transaction, evidence of local linguistic practices, other communications among or by the parties, the parties' earlier or subsequent dealings with one another, and other relevant circumstances surrounding the production and the parties' understanding of the interpretive object. The interpretive output is a meaning associated with the interpretive object-which might be the literal meaning of those words in some language or dialect, their use meaning, or the parties' legally relevant beliefs and intentions. In legal interpretation, the interpretive output serves as input for legal construction, or the determination of legal effects. The process of applying an interpretive altering rule can therefore be represented as follows:

Figure 3
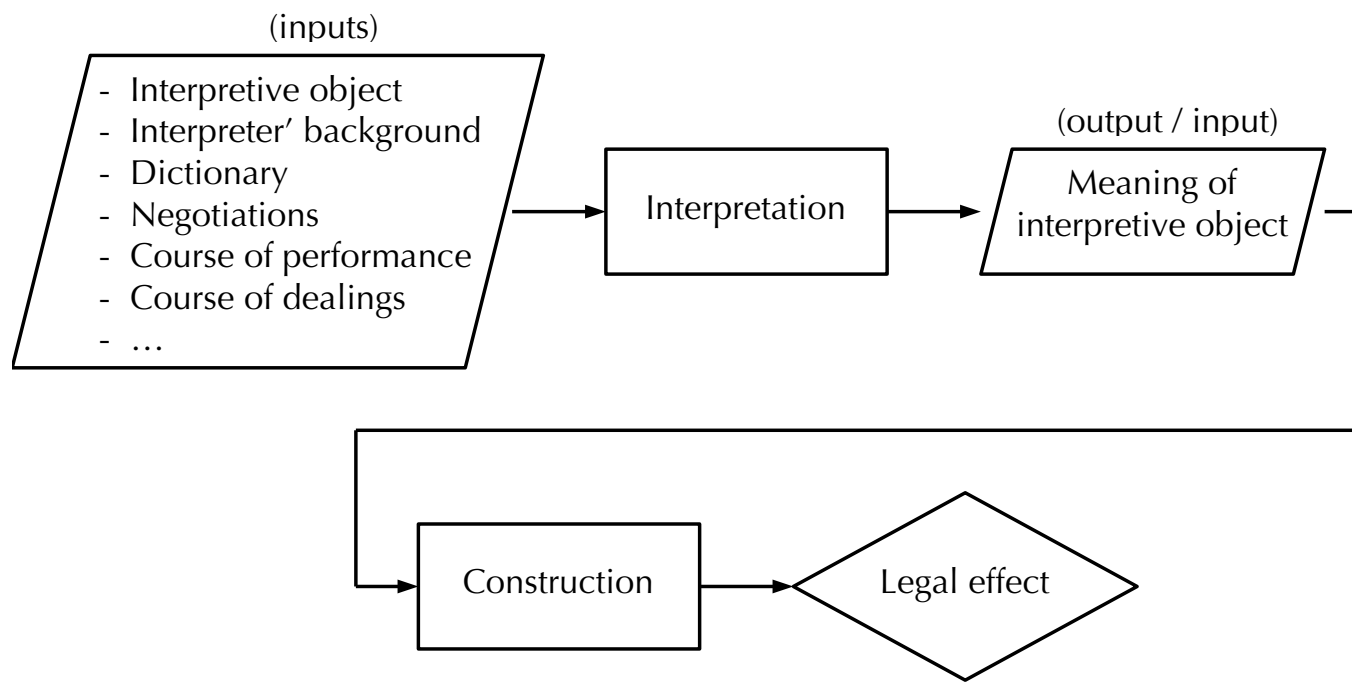

What inputs should go into contract interpretation? Scholars have mounted general defenses of both textualist and contextualist approaches. But the choice of interpretive inputs is not a binary one. Any given rule of

${ }^{94}$ The indeterminacy of interpretation renders the analogy is imperfect. See Donald Davison, Radical Interpretation and Belief and the Basis of Meaning, in Inquiries into Truth and Interpretation 125 \& 141 (1984). 
interpretation can permit more or less evidence depending on the types of evidence it authorizes (a rule of contract interpretation might permit, for example, usage of trade but not course of performance), on when that evidence is allowed in (always, only when the literal meaning is ambiguous, only in informal or nonintegrated communications, etc.), on who may consider the evidence (only the judge, also the jury), and so forth. The question is not simply whether or not to limit the interpretive domain to the text and a dictionary, but how much evidence of what type to allow under what circumstances, where the possible answers include "None ever," "All always," and many points between. ${ }^{95}$

I will use the terms thick and thin to describe the relative quantity of inputs a legal rule of interpretation permits. Rules of interpretation that permit more interpretive inputs are thicker, those that permit fewer interpretive inputs are thinner. Textualist rules of interpretation are at the far thin end of the spectrum. Schwartz and Scott suggest that the minimum interpretive domain here includes only "the parties' contract, a narrative concerning whether the parties performed the obligations that the contract appears to require, a standard English language dictionary, and the interpreter's experience and understanding of the world." ${ }^{\prime \prime 6}$ Fully contextualist approaches lie at the thicker end of the spectrum. Here the interpretive inputs might also include "(1) the parties' practice under prior agreements; (2) the parties' practice under the current agreement; (3) testimony as to what was said during the negotiations; (4) written precontractual documents (memoranda, prior drafts, letters); and (5) industry custom relevant to determining what the agreement's words meant to the contracting parties." ${ }^{197}$

The choice among thicker and thinner forms of interpretation is related to, but distinct from, the choice between, on the one side, literal meaning and, on the other, use meaning or actual agreement. The connection should be obvious. Because an utterance's literal meaning is its

${ }^{95}$ See Smith, supra note 10 at 1157-66 (identifying ways that rules can be designed to achieve a "differential formalism"); Katz, supra note 10 at 51519 (observing several ways in which courts can permit more or less evidence in interpretation).

${ }^{96}$ Schwartz \& Scott, supra note 89 at 572.

${ }^{97}$ Id. Schwartz and Scott's lists are not exhaustive. Thus the current edition of Williston maintains that even when a writing is integrated the interpreter should consider surrounding circumstance such as "the commercial or other setting in which the contract was negotiated and other objectively determinable factors that give a context to the transaction between the parties," including "whether one or both parties was new to the trade, whether either or both had counsel, and the nature and length of their relationship, as well as their age, experience, education, and sophistication." 11 Williston on Contracts $\S 32: 7$ (4th ed. 2016). 
conventional meaning in some language, in many cases a dictionary and the rules of grammar are enough to identify literal meaning. Because use meaning and the parties' actual agreement can depart from literal meaning, context evidence is more relevant to determining either. In short, thin interpretive rules are likely to be more accurate when interpreting a speech act's literal meaning than when interpreting its use meaning or the parties' actual agreement.

It does not follow that other interpretive inputs are never relevant to determining a speech act's literal meaning. I have already identified several ways that context evidence can help determine literal meaning-when there is an ambiguity, when a word's conventional meaning turns on the circumstances of its utterances, and when the parties are speaking a local dialect. Contrariwise, as the discussion of plain meaning rules will illustrate, it is possible to interpret the use meaning or the parties' actual agreement on a very thin interpretive base. In short, literal meaning formalism does not preclude a thick interpretive base, and the interpretation of use meaning or actual agreement is compatible with evidentiary formalism.

\subsubsection{Plain meaning rules}

Although a perspicacious theory of legal interpretation should, following Wigmore, distinguish between the legally relevant meaning and the permissible evidence of that meaning, in practice the two questions are often answered together. Both are components of so-called plain meaning rules. Just what courts mean by "plain meaning" is not always plain. This section describes one variation, relying primarily on New York case law.

A plain meaning rule must answer two questions: When does the rule apply? And: What does the rule require?

$I$ address the first question in Part Four, which discusses the rules governing integration. For now a summary answer suffices. Courts typically apply plain meaning rules when any of three conditions are satisfied: the parties have expressly agreed that their agreement shall be interpreted according to its plain meaning; the parties have memorialized their agreement in an integrated writing; or the parties have executed a sealed instrument. Although in theory there are circumstances in which it would be correct to apply a plain meaning rule to oral communications, ${ }^{98}$ in practice plain meaning rules are applied only to writings.

More salient at this stage is the second question: What is a writing's plain meaning? Or what is the same, what sort of interpretation do plain meaning rules require? The answer has several parts.

${ }^{98}$ An example is the oft-mentioned theoretical possibility of an integrated oral agreement. Similarly, parties might orally agree that their oral agreement shall be interpreted according to its plain meaning. 
Klass: Contract Exposition and Formalism

First, plain meaning rules are strongly associated with textualism, or evidentiary formalism. Illustrative is the New York Court of Appeals' statement in W.W.W. Associates, Inc. v. Giancontieri:

[W] hen parties set down their agreement in a clear, complete document, their writing should as a rule be enforced according to its terms. Evidence outside the four corners of the document as to what was really intended but unstated or misstated is generally inadmissible to add to or vary the writing. ${ }^{99}$

Extrinsic evidence may be introduced when the writing is unclear, that is, ambiguous. But whether or not the writing is ambiguous is also to be determined from the text itself. "[E]xtrinsic and parol evidence is not admissible to create an ambiguity in a written agreement which is complete and clear and unambiguous upon its face."100

This very narrow interpretive base gives considerable weight to a writing's literal meaning. Without extensive extrinsic evidence, words' conventional meaning is often all that remains. This raises the question of which literal meaning should provide the starting point for interpretation: local meaning, when evidence of a local dialect exists, or the common meanings found in dictionaries. Although there is not a great deal of case law on the question, New York courts appear to hold that when local meaning departs from common meaning-when the parties are speaking in dialect-local meaning controls. "Technical words in a contract must be taken in a technical sense unless the context of the instrument or a usage which is applicable clearly indicates a different meaning." ${ }^{101}$ As noted

\footnotetext{
${ }^{99}$ W.W.W. Assocs., Inc. v. Giancontieri, 77 N.Y.2d 157, 162 (1990). See also R/S Assocs. v. N.Y. Job Dev. Auth., 98 N.Y.2d 29, 32 (2002).

${ }^{100}$ Id. at 163 (quoting Intercontinental Planning v. Daystrom, Inc., 24 N.Y.2d 372, 379 (1969)).

101 Nau v. Vulcan Rail \& Constr. Co., 286 N.Y. 188, 198 (1941) (construing several terms used in patents and patent practice, and concluding that the agreement "was plain and unambiguous on its face"). See also HNC Realty Co. v. Bay View Towers Apartments, Inc., 409 N.Y.S.2d 774, 780 (1978) ("Parol evidence would have been admissible to introduce proof of usage and custom and to define the meaning intended by the parties of the term 'surety payment bond' as used in the contract."); Estate of Hatch by Ruzow v. Nyco Minerals Inc., 666 N.Y.S.2d 296, 298 (1997) ("Moreover, technical words are to be interpreted as usually understood by the persons in the profession or business to which they relate, and must be taken in the technical sense unless the context of the instrument or an applicable usage or the surrounding circumstances clearly indicate a different meaning." (dicta, internal quotation marks omitteed)).
} 
above, Williston, in the first edition of his treatise is unequivocal on the question. "That the local standard would be applied . . . seems to have been early settled. Even though the local standard led to a construction opposed to the literal meaning of the language this was true." ${ }^{102}$ Under a local meaning rule, the interpretive inputs must be expanded beyond the text to include at least evidence of local dialects. "Neither, in the construction of a contract among merchants, tradesmen, or others, will the evidence [of local usage] be excluded because the words are in their ordinary meaning unambiguous." ${ }^{103}$ I assume going forward that plain meaning rules are therefore not strictly textualist, but permit evidence of local conventional meanings.

Although evidentiary formalism gives much more weight to literal meanings, New York courts do not adhere to literal meaning formalism. Giancontieri also states that the writing is to be "read as a whole to determine its purpose and intent." ${ }^{104}$ Or as the New York Court of Appeals explained in an earlier case: "The meaning of a writing may be distorted where undue force is given to single words or phrases. We read the writing as a whole. We seek to give to each clause its intended purpose in the promotion of the primary dominant purpose of the contract." ${ }^{105}$ This

But see Mazzola v. Cty. of Suffolk, 533 N.Y.S.2d 297, 297 (1988) ("The words and phrases used in an agreement must be given their plain meaning so as to define the rights of the parties, and in this regard, it is common practice for the courts of this State to refer to the dictionary to determine the plain and ordinary meaning of words to a contract." (internal citation omitted)).

${ }^{102} 2$ Williston (1st ed) $\S 608,1172$.

103 Id. at 1172 (quoting Brown v. Byrne, 3 E. \& B. 703). In fact, Williston suggests expanding it beyond even this. See, e.g., id. at $\S 618,1198$ ("The circumstances under which a writing was made may always be shown. The question the court is seeking to answer is the meaning of the writing at the time and place when the contract was made; and all the surrounding circumstances at that time necessarily throw light upon the meaning of the contract." (citation omitted)). Although there are strong formalist elements in the first edition of his treatise, Williston focuses more on difference between meaning and intent, and he does not espouse a plain meaning rule in the contemporary sense.

${ }^{104}$ Id. at 162.

${ }^{105}$ Empire Properties Corp. v. Manufacturers Trust Co., 43 N.E. 2d 25 (N.Y. 1942). See also Fleischman v. Furgueson, 119 N.E. 400, 401 (N.Y. 1918) ("In construing a contract the whole instrument must be considered and from such consideration a conclusion reached as to what the parties intended to do or sought to accomplish."); Wolkind v. Berman, 232 A.D. 47, (N.Y. App. Div. 1931) ("The intent of the parties is determined by considering the instrument which memorializes the agreement of the parties 
emphasis on interpreting document as a whole in light of its apparent purpose takes interpretation beyond literal meaning to considerations of use meaning and the parties' apparent beliefs and intentions.

In Giancontieri the court found that the purpose of the clause at issue corresponded to its literal meaning. ${ }^{106}$ But literal and use meaning can come apart even in very thin forms of interpretation. In William C. Atwater \& Co. v. Panama R. Co., for example, the New York Court of Appeals considered the meaning, in an installment contract for the sale of coal, of the following provision: "Any portion of the tonnage remaining unshipped at the date of expiration of this agreement shall be considered cancelled without notice. ${ }^{\prime 107}$ The sentence's literal meaning would have released both parties from liability for any coal unshipped by the end of the installment period. The buyer therefore attempted to invoke it to avoid liability for coal unshipped as a result of the buyer's own unexcused refusal to accept earlier shipments. Reading the agreement as a whole, however, and in light of the seller's option to reduce installments after a buyer breach, the court concluded that the clause was intended to apply only to coal that remained unshipped as a result of the seller's exercise of that option. "Reason, equity, fairness-all such lights on the probably intention of the parties-show what the real agreement was." ${ }^{108}$ In short, the writing's use meaning controlled, at the expense of its literal meaning. ${ }^{109}$

Williston, in the first edition of his treatise, explained the rule that produces such outcomes:

as a whole."). Even more radical are early statements by the Illinois Supreme Court:

The rule is that the intention of the parties must govern, but that intention is not to be sought merely in the apparent meaning of the language used, but that the meaning of the language used may be enlarged or limited according to the true intent of the parties, as made manifest by the various provisions of the contract considered as a whole.

Street v. Chicago Wharfing and Storage Co., 41 N.E. 1108, 1111 (IIl. 1895). And: "Particular expressions will not control where the whole tenor or purpose of the instrument forbids a literal interpretation of the specific words." McCoy v. Fahrney, 55 N.E. 61, 63 (III. 1899).

10677. N.Y.2d at 163 ("[T] he face of the contract reveals a "logical reason" for the explicit provision that the cancellation right contained in paragraph 31 should run to the seller as well as the purchaser." (citation omitted)). 107159 N.E. 418 (N.Y. 1927).

108 Id. at 419 .

${ }^{109}$ For other examples, see Washington Construction Co. v. Spinella, 84 A.2d 620 (N.J. 1951); Motorsports Racing Plus v. Arctic Cat Sales, 666 N.W.2d 320 (Minn. 2003). 
[I]n giving effect to the general meaning of a writing particular words are sometimes wholly disregarded, or supplied. Thus "or" may be given the meaning of "and," or vice versa, if the remainder of the agreement shows that a reasonable person in the position of the parties would so understand it. ${ }^{110}$

When the whole of a writing evinces a purpose contrary to the literal meaning of one of its clauses, the clause's use meaning and the parties' apparent intentions control. Plain meaning should not be confused with literal meaning.

In sum, New York's plain meaning rule has three components: The first is a high degree of evidentiary formalism. The interpretive inputs should include only the text, a dictionary, any extrinsic evidence of local conventional meanings, and the interpreter's background understanding of the English language and the world. Second, when interpreting the text's literal meaning, priority should be given to demonstrable local meanings over common ones. That said, and third, the goal of interpretation is to identify the text's use meaning, to the extent it can be gleaned from the agreement as a whole. Although a text's plain meaning often is its literal meaning, sometimes the document as a whole will indicate a purpose at odds with that literal meaning, in which case the parties' probable intentions control. The output of this interpretive process is the text's plain meaning. Only when the plain meaning is ambiguous or otherwise fails under the relevant altering rule to determine the legal state of affairs may the interpreter look to other interpretive evidence of the words' use meaning or the parties' actual beliefs and intentions.

There is more to say about plain meaning rules. I have not, for example, discussed the respective roles of the judge and jury. ${ }^{111}$ Nor do other states follow New York in all the details of the above rule, or are New York courts completely consistent in the rule's application or articulation. But the above account provides a useful example for an assessment of when and where lawmakers should adopt interpretive formalism, which is the project of the next Part.

\section{Design Considerations}

Having identified two general forms of formalism in contract law, I now consider how and when each might be deployed. How formalist should the rules of contract interpretation and construction be? This is a design question. It asks what sorts of altering rules best serve contract law's

1102 Williston (1st ed.) $\S 619,1199$.

${ }^{111}$ See, e.g., Nucci v. Warshaw Const. Corp., 12 N.Y.2d 16, 20 (1962) ("The interpretation of written contracts ordinarily presents a question of law for the court."). 
purpose or purposes. In order to answer it, we therefore need to know something about the goals of contract altering rules. What are such rules meant to do? When do they succeed? When do they fail?

The analysis that follows adopts the following working hypothesis: the primary goal of contract exposition, stated at a high level of generality, is to accurately identify how the parties actually intended and understood their words and actions. ${ }^{112}$ Or as courts regularly intone, "[t]he fundamental, neutral precept of contract interpretation is that agreements are construed in accord with the parties' intent." ${ }^{113}$ This is not to say that the parties' intentions and understandings always control, or that contractual obligations are designed to perfectly mirror them. Sometimes the parties do not share an intent, in which case the law must look elsewhere-the problem that animates the objective theory. Even when the parties are in full agreement, contract law might not give full effect to their shared intentions-for example, if their agreement is contrary to public policy. And sometimes rules of construction are designed to favor one outcome or another. But the parties' intent, or some proxy for it, is generally the starting point. Contract law is designed to condition parties' legal obligations on their actual intentions and understandings. The goal is to enforce, ceteris paribus, the parties' actual agreement.

It does not follow that the rules of contract law will always direct courts to seek parties' actual agreement, intentions, beliefs, etc. This is obviously so when the parties have different intentions or understandings. When there is no actual agreement or shared understanding, the legal state of affairs must turn on other aspects of the parties' transaction. Alternatively or in addition, lawmakers might not trust legal decision makers to correctly identify the parties' actual agreement. Or the costs of accurately identifying their actual agreement might be higher than lawmakers are willing to pay. Finally, rules of construction are sometimes designed to promote social interests that do not correspond to one or both parties' actual intentions. For these and other reasons, contract altering rules often employ proxies:

${ }^{112}$ For defenses of this claim, see Lawrence M. Solan, Contract as Agreement, 83 Notre Dame L. Rev. 353 (2007); E. Allen Farnsworth, "Meaning" in the Law of Contracts, 76 Yale L.J. 939 (1967).

${ }^{113}$ Greenfield v. Philles Records, Inc., 98 N.Y.2d 562, 569 (2002). A few other examples: "The primary goal in interpreting contracts is to determine and enforce the parties' intent." Old Kent Bank v. Sobczak, 243 Mich. App. 57, 63 (2000). "Under statutory rules of contract interpretation, the mutual intention of the parties at the time the contract is formed governs interpretation." AIU Ins. Co. v. Superior Court, 51 Cal. 3d 807, 821 (1990) (citing Cal. Civ. Code $\S 1636$ ). "The cardinal rule for interpretation of contracts is to ascertain the intention of the parties and to give effect to that intention, consistent with legal principles." Bob Pearsall Motors, Inc. v. Regal Chrysler-Plymouth, Inc., 521 S.W.2d 578, 580 (Tenn. 1975). 
formalities, literal meaning or use meaning, thin interpretation. All serve as relatively cheap and, one hopes, generally accurate stand-ins for the parties' actual intent and understandings of their words and actions.

Another way of putting this is that although the principal goal of contract altering rules is to identify parties' actual agreements, intentions and understandings, accuracy in that endeavor is not the only factor to consider when designing such rules. The law does not and should not seek accuracy at all costs. In the discussion that follows, I identify several additional factors that should go into the choice of altering rules. A perspicacious account of the design of contract altering rules, including when to adopt formalist rules of one type or another, requires attention to accuracy, transaction costs, predictability, responsiveness to the law, and relational costs, as well as policy goals independent of the parties' intent. ${ }^{114}$ These factors reappear in the analysis of each form of formalism that I have identified, though they manifest themselves in different ways.

The first section of this Part examines formalistic altering rules. The second discusses interpretive formalism and plain meaning rules.

\subsection{Formalities}

The early twentieth century saw a general move away from contract formalistic altering rules, exemplified by the decline of the seal. But formalities can be extremely useful legal tools. In order to understand just when they are useful, we need a few concepts from legal theory: the ideas of juristic acts and of power-conferring rules.

\subsubsection{Juristic and nonjuristic altering rules}

Formalistic altering rules condition legal change on the use of a formality. The first thing to notice about formalities is that they are typically designed for users who intend the legal outcomes that attach to them. ${ }^{115}$ As I observed in section 2.1, a formality like the seal or "F.O.B." is a tool that parties can use to effect legal change when they wish. Formalities are therefore designed primarily for what German legal theorists call "Rechtsgeschäfte," or juristic acts:

The juristic act . . . is a declaration of private will directed at the realization of a legal effect, an effect that follows on the authority of

${ }^{114}$ For other lists of relevant factors, see Katz, supra note 10 at 522-36; Eric A. Posner, The Parol Evidence Rule, The Plain Meaning Rule, and The Principles of Contractual Interpretation, 146 U. PA. L. REV. 533, 543-47 (1998).

115 "Typically" because social policies can also figure into the design of formalities, as illustrated by the old legal reading of "children" in testamentary documents described in section 2.1 above. 
Klass: Contract Exposition and Formalism

the legal system because it is willed. The essence of the juristic act is found in the fact that a will directed at the realization of the legal effect is confirmed, and that the legal system issues a judgment, in recognition of that will, that gives legal effect to the desired legal arrangement. ${ }^{116}$

A juristic act is one that can be translated into a sentence that begins, "I/we hereby determine that ...," where the ellipsis is replaced by a proposition that describes a legal change, as in, "We the Congress of the United States hereby enact ..." or "I hereby determine that upon my death, my property shall be distributed as follows ..." Although Anglo-American legal theorists have not paid much attention to the category of juristic acts, ${ }^{117}$ they are ubiquitous in the law. Examples include legislative votes, executive orders, judicial decrees, marriage licenses, formal wills, and transfer deeds. All are expressions of the speaker's intention to change the legal state of affairs by the very expression of that intention.

A juristic act succeeds in effecting a legal change when the intended "legal effect ... follows on the authority of the legal system." That is, a juristic act succeeds when there is an authorizing law that says that the speaker can effect the relevant legal change by expressing, in the right way, her intention to do so. Such authorizing laws are what H.L.A. Hart calls "power-conferring rules." They "provide that human beings may by doing or saying certain things introduce new [laws], extinguish or modify old ones, or in various ways determine their incidence or control their operations." ${ }^{118}$ Power-conferring laws that identify acts sufficient to effect the relevant legal change are juristic altering rules.

Formalities such as the seal and "F.O.B." are tools for performing juristic acts. But notice that not all juristic acts employ formalities. Recall Williston's Model Written Obligations Act: "A written release or promise, hereafter made and signed by the person releasing or promising, shall not be invalid or unenforceable for lack of consideration, if the writing also contains an additional express statement, in any form of language, that the signer intends to be legally bound." ${ }^{119}$ The rule requires a juristic act: the signer's "express statement . . . that the signer intends to be legally bound."

\footnotetext{
${ }^{116} 1$ Motive zu dem Entwurfe eines Bürgerlichen Gesetzbuches für das Deutsche Reich, 126 (Berlin \& Leipzig, J. Guttentag 1888) (Ger.) (author's translation).

117 The great exception was John Henry Wigmore. See 5 John Henry Wigmore, A Treatise on the Anglo-American Law of Evidence in Trials at Common Law, $\S 2401,238$ (2d ed. 1924) (describing the category of "jural acts"). The idea of a juristic act is essential to Wigmore's account of the parol evidence rule.

${ }^{118}$ H.L.A. Hart, The Concept of Law 81 (2d ed. 1994).

${ }^{119}$ Model Written Obligations Act, supra note 82.
} 
And it includes a formal requirement: the expression must be in a signed writing. But the rule expressly abjures a requisite formality. The statement may be "in any form of language." All that is necessary is that the statement have the right literal meaning.

Nor are all contract altering acts-and this is absolutely crucialjuristic ones. Contracts are distinguished from constitutions, statutes, regulations, deeds, wills and oaths of office by this fact: in many instances contract law does not require that parties express an intent to alter their legal situation in order to do so. The most obvious example is the conditions of contractual validity. The creation of an informal contract requires only an agreement for consideration. Consider the following Second Restatement example of an implied-in-fact contract:

A, on passing a market, where he has an account, sees a box of apples marked "25 cts. each." A picks up an apple, holds it up so that a clerk of the establishment sees the act. The clerk nods, and A passes on. A has promised to pay twenty-five cents for the apple. ${ }^{120}$

Here there is no "declaration of private will directed at the realization of a legal effect." In fact, there is not even an express nonlegal agreement. All we have are two nonlinguistic but in context meaningful acts-holding the apple up and a nod in response-that together establish that an agreement has been reached. That is enough, according to the conditions of contractual validity, to create a contract. As Section 21 of the Second Restatement puts the point, "[n]either real nor apparent intention that a promise be legally binding is essential to the formation of a contract." ${ }^{\prime 21}$ The same holds true of acts that determine the content of contractual obligations. Thus UCC section 2-313 provides that any affirmation of fact, description of goods, or sample or model made by the seller that is part of the basis of the bargain is enough to create a warranty, explaining, "[i]t is not necessary ... that the seller use formal words such as 'warrant' or 'guarantee' or that he have a specific intention to make a warranty." 122 Other familiar examples include rules governing offers, modifications, waivers, repudiations and releases. The altering acts that determine the validity and content of contracts often need not express an intent to effect legal change. They can but need not be juristic acts.

The altering acts that figure into contract law can therefore be divided up as follows:

${ }^{120}$ Restatement (Second) of Contracts $\S 4 \mathrm{cmt}$. a, ill. 2 .

${ }^{121}$ Restatement (Second) of Contracts $\S 21$ (1981). For more on this and related rules, see Klass, Intent to Contract, supra note 22, at 1443-60.

${ }^{122}$ U.C.C. § 2-313(2). 


\section{Figure 4}

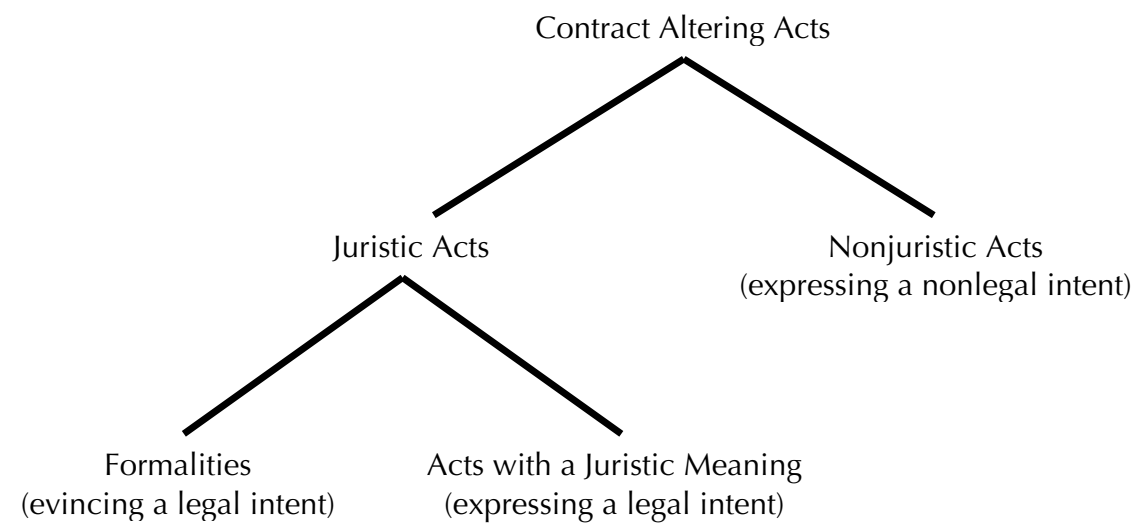

Successful juristic altering acts effect legal change by expressing or evincing an intention to do so. Nonjuristic altering acts effect legal change without necessarily expressing or evincing an intention to do so. Juristic acts can then be further divided between those that employ formalities and those that do not. Formalities are effective in virtue of their form alone. Other juristic altering acts are effective in virtue of their meaning. Each of the three types of acts effects a legal change due to an associated altering rule. We can therefore also divide altering rules into juristic and nonjuristic, depending on the type of altering act they require. Juristic altering rules are what Hart calls power-conferring rules. We can further divide juristic altering rules into formalistic and interpretive ones, depending on whether they specify a formality or an act with the right meaning as sufficient to effect the legal change.

This taxonomy entails something important about when lawmakers should adopt formalistic altering rules like the seal or "F.O.B." Such rules make sense when the goal is to give persons the power to purposively change the existing legal state of affairs. Just when this is so is a deeper question than this article can answer. ${ }^{123}$ But the many contract rules that give legal effect to nonjuristic acts suggest that contract law often seeks to do more than give individuals the power to change their legal situation when they wish. Many contract altering rules determine the legal situation based on parties' nonlegal words and acts. If, for example, an exchange agreement creates a contract whether or not the parties were thinking about legal liability, or if a seller's bare representation about the quality goods is enough to create an express warranty, a plausible explanation is that we sometimes want to impose contractual obligations for reasons other than the parties' intent to undertake them. Where the reason for imposing

${ }^{123}$ For more on the question, see Gregory Klass, Three Pictures of Contract: Duty, Power and Compound Rule, 83 N.Y.U. L. Rev. 1726 (2008). 
Klass: Contract Exposition and Formalism

liability does not turn on the speaker's legal intent, a formalistic altering rule will not serve.

\subsubsection{When and how formalities work}

Formalistic altering rules work when the goal is to give parties the power to alter their legal situation when they wish. Here too there is a choice: between adopting a formalistic altering rule, an interpretive one, or some combination of the two. In making that choice, lawmakers should consider five factors: accuracy, transaction costs, predictability, relational costs and party responsiveness.

Two important advantages of formalities are low transaction costs and high predictability. Formalities are typically cheap for knowledgeable parties to produce. Parties need only use the magic words or symbols to achieve the desired legal effect. And formalities are cheap for adjudicators to construe. Correct use of the formality can obviate the need for additional evidence or interpretation of the parties' legal intent. Finally, formalistic altering rules provide highly predictable outcomes. Contracts casebooks are filled with cases in which the best interpretation of the parties' words and actions is uncertain. By avoiding interpretation altogether, formalities achieve greater predictability. Parties who know the code will know the legal effect of their words and actions. To the extent that lawmakers want to make it easy for parties to achieve the legal effects they desire, ${ }^{124}$ formalities appear to be the way to go.

If there is a worry about formalities, it lies in their accuracy with respect to parties' actual intentions. Because we are in the world of juristic altering rules, "accuracy" here refers to the ability to correctly identify when a legal actor intends to effect the legal change associated with the formality. Joseph Raz describes the connection between power-conferring rules, legal intent and formalities as follows:

[The choice-promoting function of legal powers] explains why they are exercised either by special formal and ceremonial acts as in making a deed or getting married, or by ordinary actions whose legal consequences approximate to their non-legal and obvious consequences, as in making a contract. It also explains why most legal powers are exercised by acts with only negligible nonnormative consequences, like signing, so that there are few reasons for or against doing them apart from their legal or other normative consequences. ${ }^{125}$

${ }^{124}$ See the discussion of the possible advantages of impeding altering rules later in this section.

${ }^{125}$ Joseph Raz, Voluntary Obligations and Normative Powers (pt. 2), in 46 Proc. Aristotelian Soc'y 79, 81 (Supp. 1972). 
A formality misfires when a legal actor's intent does not correspond to the legal effect of the words she uses. As Ian Ayres observes in his account of altering rules, lawmakers should worry about both Type I and Type II errors of this sort, false positives and false negatives. ${ }^{126}$

A Type I error is the use of a formality absent an intent to effect the associated legal change. The risk of such errors was among the arguments in the early twentieth century for abolishing the seal. In 1915 Judge Fredrick Crane lamented the degradation of the seal from impressed wax to the "scrawl of a pen," without attaching any "ceremony and solemnity to the execution of important instruments, by means of which the attention of the parties is more certainly and effectually fixed." ${ }^{\prime 27}$ The result, Crane argued, was what we would today call Type I errors. "While the necessity for the private seal has virtually gone, its use still remains, with many serious and ensnaring effects. A study of the cases will convince one that people make use of the printed or written 'L.S.' without fully appreciating its effect." ${ }^{128}$ Formalistic boilerplate can be another trap for the unwary. Recall Boardman's observation that standard clauses in contemporary insurance contracts are often best understood as "a private conversation between drafters and the courts." ${ }^{129}$ The consumer who relies on the literal meaning of the words in her policy might not understand their legal effect. The old rule for construing "children" in a testamentary document probably also resulted in Type I errors. A testator who did not know the legal meaning of the word might use it expecting that property would go to all of his or her children, though its legal operation would disinherit children born out of marriage.

The accuracy of formalities therefore depends in large part on parties' sensitivity to legal rules. I will say that parties are responsive when they are aware of a law and craft their words and actions in light of it. Responsive parties are sometimes described as "sophisticated." But responsiveness is not a personality trait. A party might, for example, be more responsive to the legal regime during some stages of a transaction and less responsive at others. And as every corporate counsel knows, even experienced businesspeople-whom we might naturally think of as sophisticated-sometimes do not take the legal effects of their words and actions into account. ${ }^{130}$

\footnotetext{
${ }^{126}$ Ayres, supra note 22, at 2066.

${ }^{127}$ Frederick E. Crane, The Magic of the Private Seal, 15 Colum. L. Rev. 24, 24 (1915) (quoting Chancellor Kent in Warren v. Lynch, (N.Y. 1810) 5 Johns. 238).

${ }^{128} / d$. at 25 .

${ }^{129}$ Boardman, supra note 93.

${ }^{130}$ The story of pari passu clauses in sovereign debt contracts provides a nice example of unresponsive sophisticated parties. See supra note 51.
} 
Klass: Contract Exposition and Formalism

Responsive parties are able to use legal formalities to their benefit. Unresponsive parties, on the contrary, are less likely to know or understand a formality's legal effect. Type I errors are especially likely when unresponsive parties sign agreements drafted by responsive parties-when only one side knows the code.

A potential solution is education. The formality might be designed, for example, to convey information to its users, turning unresponsive parties into responsive ones. ${ }^{131}$ As Crane argued, ceremonial formalities can impress on users that the act has serious consequences. Or the formality might be designed to tell users about its legal effects. If contract boilerplate is problematic because the ordinary meaning of a its words do not correspond to their legal effect, the solution would seem to be to require words that say, in ordinary language, just what those legal effects are. Although not a formality in the technical sense used here, the Consumer Finance Protection Bureau's model mortgage disclosure form provide an example. Through empirical study, regulators identified a form of expression that is more likely to inform consumers of the terms of the transaction. ${ }^{132}$ In short, formalities might be designed to provide not only a clear path to certain legal results, but also to clarify to their users what those results are.

That said, the more information lawmakers attempt to pack into a formality, the more expensive it is to use. This is an example of a common dynamic Ayres identifies in the design of altering rules: a tradeoff between transaction costs and error reduction. ${ }^{133}$ Even more concerning is empirical evidence that such education does not work. If consumers or other unresponsive parties do not read the agreements they sign, it does not matter what words the law requires for their effectiveness. ${ }^{134}$ Whether,

${ }^{131}$ For more on the design error-reducing altering rules generally, see Ayres, supra note 22, at 2068-84.

${ }^{132}$ Available at: http://www.consumerfinance.gov/owning-a-home/closingdisclosure/. For background on the form's design, see Federal Trade Commission, Report: Improving Consumer Mortgage Disclosures: An Empirical Assessment of Current and Prototype Disclosure Forms: A Bureau of Economics Staff Report (June 13, 2007), available at: https://www.ftc.gov/reports/improving-consumer-mortgage-disclosuresempirical-assessment-current-prototype-disclosure.

The mortgage form is not a formality in my sense of the term because failure to use it does not render the loan invalid, but merely subjects the lender to potential legal liability. 12 U.S.C. §§ $2605(\mathrm{f}) \& 2615$. 133 Ayres, supra note 22, at 2061-63.

${ }^{134}$ See Yannis Bakos, Florencia Marotta-Wurgler \& David R. Trossen, Does Anyone Read the Fine Print? Consumer Attention to Standard Form Contracts, 43 J. Legal Stud. 1 (2014) (finding that virtually no consumers read online end user license agreements); Omri Ben-Shahar \& Carl E. 
when and how formalities might be designed to avoid Type I errors is an empirical question that is likely to receive different answers in different contexts, depending on factors such as the identity of the parties and the nature of the transaction between them.

An alternative solution is to make the effects of the formality defeasible - to permit interpretive evidence that a user or users did not in fact intend the associated legal result. And in fact, many formalistic altering rules have this feature. Thus the section 2-319 payment rules for "F.O.B." apply only "unless otherwise agreed." ${ }^{135}$ Where the parties have agreed, for example, that payment is to be made by a letter of credit, the buyer is not required to make tender of payment against the required documents, as the rule otherwise prescribes. ${ }^{136}$ And as noted above, many states now treat the seal as creating only a rebuttable presumption of consideration. The costs in predictability and judicial economy are obvious. When a formality is nondefeasible, its use ends the inquiry. Some, though not all, of that advantages is lost if parties are permitted to introduce interpretive evidence to defeat the formality.

Sometimes, however, lawmakers might consider Type I errors desirable. Recall the early, nondefeasible rule for testamentary uses of "children," which read the word to refer only to children by marriage. One might guess that the purpose of this rule was not, or not only, to effect testators' intentions, but to favor some offspring over others. Here the formality is used not, or not only, as evidence of the party's intent, but to promote other social goals. Attaching an automatic legal effect, defeasible or nondefeasible, to an everyday word can also be a tool for guiding parties' to legal results that they might not intend.

Type II errors are false negatives and occur when parties wish to achieve a certain legal result but fail to satisfy an altering rule that would secure it. With respect to formalistic altering rules, a Type II error happens when parties who want to achieve a legal effect do not use the magic words, whether because they do not know them or because they make a mistake in expression. The solution here is rules that say that correct use of the formality is sufficient but not necessary to effect a legal change. By also allowing parties to achieve the desired legal effect without using the formality-by stipulating that it is also enough to say words with the right meaning-lawmakers can make it easier for unresponsive parties to achieve

Schneider, More Than You Wanted to Know: The Failure of Mandated Disclosure (2014) (discussing the limited effectiveness of disclosure rules). 135 U.C.C. § 2-319(4).

${ }^{136}$ Pioneer Bank \& Trust Co. v. Seiko Sporting Goods, U.S.A. Co., 184 III. App. 3d 783, 791-92 (1989). 
the legal effects they want. In order to avoid Type II errors, formalistic altering rules should be supplemented with interpretive ones. ${ }^{137}$

Again there are tradeoffs. Like nondefeasible legal effects, a requisite formality-one that is the only path to a legal outcome-can mean greater predictability and lower costs of adjudication. If the parties have not said the magic words, they have not effected the legal change. That is no longer the case if using the formality is not the only way to reach the desired legal state of affairs.

Requisite formalities can have other advantages as well. If it is possible to design a formality to educate unresponsive parties about legal consequences, that is a reason to require its use. In such a case, the advantage from reducing Type I errors-misunderstanding of the legal effects-might outweigh the costs of any resulting Type II errors-failing to use the right words to achieve those legal effects.

Alternatively, as Ayres points out, requiring a formality might sometimes serve a desirable sorting function. "An altering rule with arbitrary language operates as a password that allows knowledgeable parties to achieve a desired result without running the risk that unknowledgeable parties will mistakenly invoke the sufficient condition." ${ }^{138}$ In other words, lawmakers might sometimes consider Type II errors among unresponsive parties to be a good thing. More generally, when there is a social interest in having parties stick with a default, it can make sense to design the altering rule to impede departures from it. ${ }^{139}$ Requisite costly formalities like recitations, waiting periods, recording taxes and the like can ensure that only those who attach a high value to the resulting legal change will take the trouble. Again, such mechanisms work only if using the formality is the only way to achieve the desired legal change. ${ }^{140}$

${ }^{137}$ Ayres provides a similar explanation of why altering rules commonly identify acts that are sufficient but not necessary to achieve legal change. Giving effect to a multiplicity of methods [to avoid the default] reduces the costs of learning the law-especially the necessity to learn the altering rules themselves. A contract law that includes necessary elements for displacement will tend to increase the cost of becoming (and remaining) informed of the requisite procedures for displacement.

Ayres, supra note 22, at 2055 (footnote omitted). See also id. at 2081-82 (arguing that the best "password altering rules . . . are nonexclusive means-and are merely sufficient safe harbors_-for achieving particular contractual concerns").

${ }^{138}$ Id. at 2081.

${ }^{139}$ Id. at 2084-96.

${ }^{140}$ Similar advantages can be secured by adding formal requirements to interpretive altering rules. 
So far I have been treating party transaction costs as if they involved only the cost of understanding and producing the formality. But formalities sometimes come with another type cost. Exchange transactions often depend on a mix of legal and nonlegal forms of trust. A party who expects to engage in multiple transactions with her counterpart might choose to perform because breach would jeopardize that future income stream. A party who engages in similar transactions with others might worry about the reputational effects of breach. Parties in close-knit communities or in longstanding relationships might trust in one another's honor, good will or moral sensitivity. These extralegal incentives can be as strong or stronger than legal ones, often add considerable value to exchange transactions, and in some cases have an intrinsic value of their own.

I have argued elsewhere that juristic formation rules that require parties to say that they want legal enforcement can in some circumstances interfere with and erode extralegal forms of trust.

Particularly at the early stages of relational contracts, where both parties understand that the transaction's value depends on their ability to work together to resolve disputes, one party's expressed attitude towards the availability of legal liability . . . might be a deal breaker. And even if the deal still happens, forcing the parties to express [such] preferences at the beginning of their relationship can erode relationship-preserving norms that would otherwise add value to the transaction. Even where expectations or preferences regarding legal liability are mutually understood, those attitudes are often better left unspoken. ${ }^{141}$

One can easily imagine situations in which forcing parties to express their legal intent with a formality might further increase those costs. As Stuart McCauley observed, "[b] usinessmen often prefer to rely on 'a man's word" in a brief letter, a handshake, or 'common honesty and decency' —even when the transaction involves exposure to serious risks." ${ }^{142}$ Here theory again hits empirics. The existence and size of such relational costs are likely to differ between different types of contractual transactions. A merger agreement between two multi-national corporations is not the same as a long-term supply contract between two local businesses, which in turn differs from a promissory exchange between friends or family members. When formalities will impose relational costs, and how large those costs will be, is an empirical question that theory can identify but not answer.

Where such relational costs exist we can expect them to be another cause of Type II errors. Parties who prefer legal liability might choose not to

${ }^{141}$ Klass, Intent to Contract, supra note 22, at 1474.

142 Stuart Macaulay, Non-contractual Relations in Business: A Preliminary Study, 28 Am. Soc. Rev. 55, 58 (1963). 
employ a requisite formality because each worries about the signal it will send the other. The design solution here is the same as above: supplementing the formality with an interpretive altering rule that provides an alternative path to the desired legal change. That rule might be a juristic one, permitting the parties to use less formal words to express or indicate their legal intent. Or it might be a nonjuristic one, identifying certain acts that make legal liability appropriate even though the parties have not expressly asked for it. ${ }^{143}$

The above analysis of when and how to employ formalistic altering rules can be summarized as follows. Formalities are primarily of use when the goal is to give parties the power to intentionally alter their legal situation. That is, formalities are primarily useful in the design of juristic altering rules. When lawmakers seek to condition the legal state of affairs on parties' nonlegal acts and expressions, formalities do not serve. And even when lawmakers want to give parties the power to change their legal obligations, formalities are not the only option. Interpretive juristic altering rules can supplement or provide alternatives to formalistic ones. When a rule applies to transactions between responsive parties-parties who know and respond to legal rules - a formality provides a cheap and predictable legal tool. But when unresponsive parties are involved, lawmakers might worry about accuracy. Type II errors can be solved pairing formalistic altering rules with interpretive ones, thereby giving parties who do not know the rule alternative and more accessible paths to effect legal change when they wish. Alternative paths can also address Type II errors among responsive parties who might wish to avoid formalities because of their relational costs. There are two possible ways to reduce Type I errors. One is education, which can be expensive and does not always work. The other is making the formality defeasible. Both alternative paths and defeasible effects, however, rob formalities of some of their advantages.

\subsection{Interpretive formalism}

Part Two analyzed plain meaning rules as employing a mix of evidentiary and literal meaning formalism. By sharply limiting the interpretive inputs, plain meaning rules give priority to literal meaning. But a plain meaning rule can also direct interpreters to consider evidence of local conventional meanings, which expands the evidentiary base. And plain meaning rules typically instruct them to evaluate individual words in light of the parties' purposes as evidenced in the document as a whole. The latter rule means that the literal meaning of the parties' words sometimes gives way to their use meaning - though less often than it would with a thicker interpretive base.

${ }^{143}$ For examples of the latter, see the analysis of spousal agreements in Klass, Intent to Contract, supra note 22, at 1488-97. 
This section considers some design considerations relevant to interpretive formalism generally, and especially plain meaning formalism. Before getting there, however, I consider a relatively common antiformalist claim: that there is no such thing as plain meaning.

\subsubsection{Plain meaning and the theory of language}

Corbin, in the first edition of his treatise, formulates the claim as follows:

[I]t can hardly be insisted on too often or too vigorously that language at its best is always a defective and uncertain instrument, that words do not define themselves, that terms and sentences in a contract, a deed, or a will do not apply themselves to external objects and performances, that the meaning of such terms and sentences consists of the ideas that they induce in the mind of some individual person who uses or hears or reads them, and that seldom in a litigated case do the words of a contract convey one identical meaning to two contracting parties or to third persons. Therefore, it is invariably necessary, before a court can give any meaning to the words of a contract and can select one meaning rather than other possible ones as the basis for the determination of rights and other legal effects, that extrinsic evidence shall be heard to make the court aware of the "surrounding circumstances," including the persons, objects, and events to which the words can be applied and which caused the words to be used. ${ }^{144}$

Corbin is arguing in effect that there is no such thing as plain meaning. ${ }^{145}$ "' $[M]$ eaning' cannot exist without a speaker or hearer," and "no word or phrase has one true and unalterable meaning." ${ }^{146}$ Meaning only happens when words are used in a particular setting for a specific purpose. The idea that words could have a meaning apart form their contextually determined use is an outdated form of magical thinking. Considered in isolation, words on the page are dead letters.

This line of thought is relatively common among antiformalists. Justice Traynor in Pacific Gas writes:

\footnotetext{
1443 Corbin (1st ed.) $\S 537$ at

${ }^{145}$ Corbin was no philosopher of language, and the paragraph is not a model of clarity. There is also a suggestion that plain meaning is unlikely to capture the parties' actual agreement. I address this worry in the next section, in the discussion of plain meaning rules and correspondence errors.

${ }^{146} / d$. at $\S 535, \ldots$ n. $15 \&$
} 
Words, however, do not have absolute and constant referents. . . . The meaning of particular words or groups of words varies with the "verbal context and surrounding circumstances and purposes in view of the linguistic education and experience of their users and their hearers or readers (not excluding judges). . . . A word has no meaning apart from these factors; much less does it have an objective meaning, one true meaning. ${ }^{\prime 147}$

Melvin Eisenberg argues, "The proper interpretation of all purposive expressions, including contractual expressions, is necessarily dynamic, because the meaning of a purposive expression is always determined in part by its context, and the context is prior to the expression. ${ }^{\prime 148}$ Farnsworth maintains, "The very concept of plain meaning finds scant support in semantics, where one of the cardinal teachings is the fallibility of language as a means of communication. ${ }^{\prime 149}$ The comments to section 212 of the Second Restatement, which concerns the interpretation of integrated agreements, assert that "meaning can almost never be plain except in a context." ${ }^{\prime 150}$ And one finds a similar claim in the comments to section 2-202 of the UCC: "This section definitively rejects ... [t] he premise that the language used has the meaning attributable to such language by rules of construction existing in the law rather than the meaning which arises out of the commercial context in which it was used."151

These arguments against the very possibility of plain meaning rest on a non sequitur. I take them to begin from two correct premises. First, use meaning is highly context dependent. Use meaning turns on the speaker's

147442 P.2d at 644-45 (quoting Arthur Linton Corbin, The Interpretation of Words and the Parol Evidence Rule 50 Cornell L.Q. 161, 187 (1965)).

${ }^{148}$ Eisenberg, supra note 8 at 27.

${ }^{149}$ Farnsworth, supra note 112 at 952. See also E. Allan Farnsworth, Contracts $\S 7.10$, _ (4th ed. 2004) ("Indeed, it is questionable whether a word has meaning at all when divorced from the circumstances in which it is used.").

${ }^{150}$ Restatement (Second) of Contracts $\S 212 \mathrm{cmt}$. b. Cf. 3 Corbin (1 st ed.) $\S 542$, __ ("[S] ome of the surrounding circumstances always must be known before the meaning of the words can be plain and clear."). A similar claim can be found in the comments to section 214 of the Second Restatement:

Words, written or oral, cannot apply themselves to the subject matter. ... Even though words seem on their face to have only a single possible meaning, other meanings often appear when the circumstances are disclosed.

Restatement (Second) of Contracts $\S 214$, cmt. b. Farnsworth was of course the final Reporter on the Second Restatement.

151 U.C.C. § 2-202 cmt. 1. 
communicative intentions, and often we can correctly identify those intentions only by considering the context in which the speaker acts. Second, because words first acquire meaning through their use, there is a sense in which use meaning is fundamental. Conventional meanings are not merely correlations between words and objects, or sentences and events. They are regular patterns of usage, of intended meanings. ${ }^{152}$ Words do not have literal meanings absent their purposive use.

We can grant Corbin both these premises and still not follow him to the conclusion that words do not have plain or literal meanings tout court. Conventional meaning is like the desire lines in a city park - the paths of wear that come from many individual trips across a grassy area. There are no desire lines absent individual choices to walk to one place or another. Nor do the worn paths constrain where people can walk. But a park's desire lines reflect patterns of choice. And a person might even use them when deciding where to walk. The analogy is not perfect. Linguistic conventions enable communication in ways that desire lines typically do not enable crossing a park. (But consider a parent pushing a stroller when the grass is long.) That said, there is this similarity: The fact that meaning is in the first instance the product of use does not entail that there are no patterns, conventions or defeasible rules of usage. And there can be such patterns, conventions and defeasible rules even if they do not fully determine the use to which words are put in a given instance, whether because literal meaning is sometimes ambiguous or because speakers sometimes make their point by flouting or otherwise departing from linguistic conventions.

This is not yet to say whether parties' contractual obligations should turn on the literal meaning, plain meaning or the fully contextually determined use meaning of what they say and do. The point is simply that the ideas of literal and plain meaning are not incoherent. When Corbin writes that " $[\mathrm{b}] \mathrm{y}$ 'interpretation of language' we determine what ideas that language induces in other persons," ${ }^{153}$ he employs an unduly narrow conception both of meaning and of legal interpretation.

\subsubsection{Two differences between interpretive formalism and formalities}

Before jumping into the analysis of interpretive formalism, it is worth noting two broad differences between formalistic altering rules and interpretive formalism.

The first turns on the distinction between juristic and nonjuristic altering rules. My discussion of formalities in section 3.1.2 drew from lan Ayres's original and important analysis of altering rules. But there is a crucial difference between Ayres's approach and mine. Ayres treats

152 See Donald Davidson, Radical Interpretation and Belief and the Basis of Meaning, supra note 94; W.V.O. Quine, Word and Object 26-79 (1964).

1533 Corbin ( 1 st ed.) $\S 534$ at 7. 
contract altering rules as instructions to the parties. "An altering rule in essence says that if contractors say or do this, they will achieve a particular contractual result." ${ }^{154}$ Ayres therefore analogizes the design of altering rules to the design of software interfaces. ${ }^{155}$ Just as a legal default is like the default margins in a word processing program, so the associated altering rule is like the commands one must execute to change those margins. Each gives users a tool to effect a change in the relevant environment. Ayres therefore suggests that altering rules that do not "give guidance about either the non-default options or the mechanisms for achieving them" are characteristic of "'immature' regimes where the accretion of precedent has not provided judicial disclosure guidance about particular mechanisms that are sufficient to achieve particular alternatives."156

Ayres's conception of altering rules as instructions is of a piece with his economic approach to contract law. Economic analysis focuses on how legal rules influence decision-making. In the case of contract law, the influence can reach not only parties' perform-or-breach decision, but also decisions they make at and around the time of formation. Economic analysis's sustained attention to those influences has provided important contributions to our understanding of contract law generally. ${ }^{157}$ Ayres's theory of altering rules, like his earlier theory of defaults, ${ }^{158}$ explores the incentives that the rules of contract construction create at the time of formation, and suggests how lawmakers can design those rules to take advantage of them. Add to this picture a recognition that our contract law is designed at least in part to empower parties to get the legal obligations they want, and it is a short step to imagining contract law as a set of instructions telling legal subjects how to achieve their legal goals.

But this captures only part of the altering rules story-the left branches in Figure 4 above. Ayres provides a theory of juristic altering rules

${ }^{154}$ Id. at 2036.

${ }^{155}$ Ayres fruitfully mines Microsoft User Experience Interaction Guidelines, which identifies general principles for how to design software interfaces. Id. at 2039-42, 2063-66, 2069-71.

$156 / d$. at 2053.

${ }^{157}$ Sophisticated economic theories of contract remedies, for example, have addressed their effects not only on the perform-breach decision, but also on many other decisions in the transaction, from pre-formation investment to post-breach mitigation. See, e.g., John H. Barton, The Economic Basis of Damages for Breach of Contract, 1 J. LEGAL STUD. 277 (1972); Richard Craswell, Contract Remedies, Renegotiation, and the Theory of Efficient Breach, 61 S. CAL. L. REV. 629 (1988); Daniel Markovits and Alan Schwartz, The Myth of Efficient Breach: New Defenses of the Expectation Interest, 97 Va. L. Rev. 1939 (2011).

${ }^{158}$ Beginning with Ian Ayres \& Robert Gertner, Filling Gaps in Incomplete Contracts: An Economic Theory of Default Rules, 99 Yale L.J. 87 (1989). 
only. It is true that, because juristic altering rules are designed to give persons the power to effect legal change when they wish, they should give guidance as to how to achieve those changes. Juristic altering rules are like instructions. But nonjuristic altering rules are different. When the goal is to condition legal outcomes on the nonlegal meaning of what the parties said and did-whether they entered into an agreement, whether a seller made a representation about the quality of the goods, whether a party expressed an intention to perform despite the nonoccurrence of a condition-it is a mistake to think of the altering rule as a set of instructions. This is not to say that responsive parties won't treat the rule that way, crafting their words and actions in light of it. But a nonjuristic altering rule's purpose or function is not to give them such guidance. It is designed to attach legal effects to the nonlegal meaning of what parties say and do. As such, it is not designed to operate as instructions to them.

Another way of putting the point is this. One reason we have interpretive in addition to formalistic altering rules, which Ayres's account makes room for, is to prevent Type II errors by parties who want the legal effect but who do not know or who misuse the magic words. A separate reason, which Ayres does not consider, is that sometimes we want legal liability to turn on the nonlegal meaning of the parties' words and actions, whether they intended that effect or not. When that is the case, only interpretive rules will do.

All this is important because an interpretive altering rule, unlike a formalistic one, might identify either juristic or nonjuristic acts as sufficient to effect legal change. The Model Written Obligations Act, for example, is a juristic interpretive rule. To apply the rule, a legal decisionmaker must interpret a party's words to see whether they contain an "express statement ... that the signer intends to be legally bound." ${ }^{159}$ The basic rule of contract formation, in distinction, is a nonjuristic interpretive rule. To apply the rule, a legal decisionmaker must interpret the parties' words and actions to determine whether "there is a manifestation of mutual assent to [an] exchange." ${ }^{160}$ The question is not whether the parties have expressed an intent to alter the legal situation, but whether their words and actions express their agreement to an exchange transaction. Whereas the goal of a formality is always to correctly identify the parties' legal intent, the goal of an interpretive altering rule might be to identify the parties' legal intent, or it might be to identify their nonlegal intent or understanding.

This difference is crucial to the design of interpretive altering rules. A formality typically works when its users know and intend to satisfy the associated altering rule. A nonjuristic interpretive altering rule, in distinction, can succeed even if the speaker is ignorant of that rule. Corbin suggests the following example:

${ }^{159}$ Model Written Obligations Act, supra note 82.

${ }^{160}$ Restatement (Second) Contracts § 17(1) (1981). 
Klass: Contract Exposition and Formalism

There seems to be no serious doubt that a mutual agreement to trade a horse for a cow would be an enforceable contract, even though it is made by two ignorant persons who never heard of a legal relation and who do not know that society offers any kind of a remedy for the enforcement of such an agreement. ${ }^{161}$

Or more familiarly, recall the Article Two rule for express warranties. All a seller needs to do to create a warranty is say something about the goods. She need not express her intent to create a warranty. ${ }^{162}$ In the case of altering rules like these, which look for nonjuristic acts, the rule can work even if the speaker is unaware of it. Whereas the design of formalistic altering rules always presupposes a minimum degree of party responsiveness - knowledge of the formality and its legal effects-the design of interpretive rules need not.

This is not to say that interpretive altering rules cannot be designed with responsive parties in mind. Many parties know the interpretive altering rules that will apply to their agreement and choose their words and actions accordingly. And, I will argue, the strength of that feedback effect affects the accuracy of formalist interpretive altering rules. When parties know that their words will be interpreted with a limited evidentiary base or according to their literal meaning, they will invest extra effort to express themselves in terms amenable to such interpretation. The more parties are likely to choose their words in light of the altering rule, the more accurate formalist approaches will be. Unlike formalistic altering rules, however, an interpretive altering rule can also function properly when the parties do not know the rule. In fact, interpretive rules can be designed for parties who are not thinking about the legal effects of their words and actions.

A second important difference between formalistic and interpretive altering rules is in the ways each can lead to erroneous outcomes. A formalistic altering rule goes awry when the formality's legal effect does not correspond to the legal actors intentions. A party might sign an agreement with the letters "L.S." printed at the bottom, for example, without understanding their legal effect, or even realizing that they have one. The same type of error can occur in interpretive altering rules. A plain meaning altering rule, for example, misfires when the plain meaning of the parties' words differs from their actual agreement, intentions or understandings. I will call such errors correspondence errors. A correspondence error occurs when a formality or legally relevant meaning does not correspond to the

1611 Corbin (1st ed.) § 34 at 135.

162 U.C.C. $\S 2-313(1)(a) \&(2)$. 
parties' actual intentions or understandings. ${ }^{163}$ Both formalistic and interpretive altering rules can generate correspondence errors.

The application of interpretive rules can result a second type of error, one that is not much of a worry in the case of formalistic rules. Adjudicators can also make errors of interpretation. If the parties are speaking in a local dialect, for example, an adjudicator without reliable evidence might mistake the literal meaning of their words in that language. Or in the application of a use meaning rule, an adjudicator might misinterpret the contextually determined objective meaning of what a speaker said. I will call errors of this type interpretive errors. The analogy in the application of a formalistic altering rule would be adjudicator error as to whether the parties employed the formality. But because formalities are designed to be easily identifiable, we such errors should be rare.

\subsubsection{When and how interpretive formalism works}

With these basic observations in hand, I now turn to the design of interpretive altering rules, with particular attention to when plain meaning rules are likely to work well.

We can begin with the question of evidence, or what Wigmore calls the "sources" of interpretation. As with other questions of evidence, the design problem can be stated in cost-benefit terms. ${ }^{164}$ The most salient benefit of permitting additional relevant interpretive evidence is, one hopes, greater interpretive accuracy. The more relevant evidence a competent interpreter has about the transaction and the surrounding circumstances, the better able she should be to correctly identify the meaning of the parties' words and actions. In short, more relevant evidence should mean fewer interpretive errors. As I've emphasized, the magnitude of that benefit depends both on the type of meaning in question and on the type of evidence at issue. If the desired interpretive output is the common literal meaning of a written agreement, evidence of trade usages and of the circumstances surrounding the transaction is often of limited value. A dictionary and the interpreter's background understanding of the language are often enough. If the desired interpretive output is a writing's local literal meaning, evidence of trade usage might bring more significant gains in

${ }^{163}$ For simplicity's sake my examples all involve Type I correspondence errors. There can also be Type II correspondence errors-when a speaker fails to perform the altering acts, formal or informal, required to achieve her desired legal outcome.

${ }^{164}$ Such cost-benefit analysis appears, for example, in Rule 403 of the Federal Rules of evidence, which provides that a "court may exclude relevant evidence if its probative value is substantially outweighed by a danger of one or more of the following: unfair prejudice, confusing the issues, misleading the jury, undue delay, wasting time, or needlessly presenting cumulative evidence." Fed. R. Evid. 403. 
accuracy, whereas evidence of the circumstances surrounding the transaction remains of lesser relevance. If the desired interpretive output is a writing's use meaning, facts such as the parties' relationship, the course of negotiations, and any performance under the agreement are likely to bring more significant gains in accuracy.

Although one can make broad generalizations about which sorts of interpretive evidence are likely to be most useful in seeking out which meanings, the accuracy gains from any given type of evidence depend on empirical facts not amenable to armchair analysis. Lisa Bernstein has argued, for example, that, "'usages of trade' and 'commercial standards,' as those terms are used by the [UCC], may not consistently exist, even in relatively close-knit merchant communities." ${ }^{165}$ If Bernstein is correct, permitting parties in the industries she studies to introduce usage of trade evidence might produce more smoke than light. In industries in which usages of trade and commercial standards do exist and are verifiable, appeal to such evidence will bring greater interpretive accuracy. Which if any industries satisfy that description is an empirical question. An additional and critical empirical question concerns the ability of judges or juries to correctly evaluate different types of evidence. More recently Bernstein has argued that "court determinations relating to the existence, content, and scope of usages are likely to be both inaccurate and highly unpredictable, as they are typically made on the basis of very limited information." ${ }^{166}$ If courts are unable to correctly evaluate one or another form of interpretive evidence, permitting that evidence might result in more interpretive errors. If evidence that would be probative in an ideal world is likely to mislead actual decision-makers, we might want to categorically exclude it. As a corollary, if adjudicators are unable to locate or correctly evaluate the interpretive evidence necessary to accurately interpret one or another type of meaning, that is a reason not to condition legal outcomes on meanings of that type.

Like formalities, evidentiary formalism should produce both cheaper, faster adjudication and more predictable outcomes. Consider the potential costs of the ruling in Pacific Gas \& Electric v. G.W. Thomas Drayage \& Rigging, ${ }^{167}$ the most famous antiformalist opinion in US law. At issue was the meaning of the words "Contractor shall indemnify Company . . . against all loss, damage, expense and liability resulting from . . . injury to property. ${ }^{\prime 168}$ The trial court was able to identify the sentence's literal

${ }^{165}$ Lisa Bernstein, The Questionable Empirical Basis of Article 2's Incorporation Strategy: A Preliminary Study, 66 U. CHI. L. ReV. 710, 715 (1999).

${ }^{166}$ Lisa Bernstein, Merchant Law in a Modern Economy, in Philosophical Foundations of Contract Law 238, 250 (G. Klass, et al. eds., 2014).

16769 Cal. 2d 33 (1968).

168442 P. $2 d$ at 643. 
meaning based only on its knowledge of the English language and perhaps a dictionary: the clause covered all property damage, and therefore covered damage to the property of the owner-party. ${ }^{169}$ This permitted the court to rule on the clause's legal effect at the beginning of the trial, narrowing the issues going forward. The California Supreme Court held that the trial court was wrong to exclude that extrinsic evidence that the parties actually understood the indemnification clause to cover only third-party property damage.

The test of admissibility of extrinsic evidence to explain the meaning of a written instrument is not whether it appears to the court to be plain and unambiguous on its face, but whether the offered evidence is relevant to prove a meaning to which the language of the instrument is reasonably susceptible. ${ }^{170}$

This is a thick use meaning rule. Its predictable effect: a protracted battle over how the parties, in the circumstances, understood the indemnification clause, with both sides introducing party witnesses, expert testimony, facts from the course of negotiations, and other extrinsic evidence, all of which would be expensive and time consuming. ${ }^{171}$ Thinner interpretive rules are relatively cheap to apply, thicker ones relatively expensive.

${ }^{169}$ In fact, the literal meaning of the clause was not quite so obvious as Traynor's opinion suggests. The opinion does not mention that the Court of Appeals looked to the meaning of "indemnifies" and the California Civil Code's definition of "indemnity" as a "contract by which one engages to save another from a legal consequence of the conduct of one of the parties, or of some other person." Cal. Civ. Code $\S 2772$ (emphasis added). Reasoning that the owner of the steam turbine "did not incur any legal liability for the damage done to its own property," the intermediate court concluded that the clause's literal meaning did not cover the damage at issue. Pac. Gas \& Elec. Co. v. G.W. Thomas Drayage \& Rigging Co., 62 Cal. Rptr. 203, 204 (Ct. App. 1967), vacated sub nom. Pac. Gas \& Elec. Co. v. G. W. Thomas Drayage \& Rigging Co., 69 Cal. 2d 33 (1968). The court went on to suggest that insofar as the clause was ambiguous, it should be construed against the owner-drafter to reach the same result. Id. at 204-05. In its brief to the California Supreme Court, the plaintiff pointed to other definitions of "indemnify" that encompassed non-legal losses. Resp. Pet. for Hearing By the Supreme Court, Pac. Gas \& Elec. Co. v. G. W. Thomas Drayage \& Rigging Co., _____ 1 Civil No. 23738 (filed Oct. 30, 1967). There was therefore a good argument, unmentioned by Traynor, that the plain meaning of indemnification clause was at least ambiguous. ${ }^{170} 442$ P. $2 \mathrm{~d}$ at 644.

171 Traynor's opinion mentions only the defendant's proffer of extrinsic evidence to prove that the parties intended the clause to cover only third- 
Evidentiary formalism also renders interpretive outcomes more predictable. By permitting testimony that the clause was in fact meant to cover only injuries to third parties, the California Supreme Court arguably created doubt where it did not exist before. Resolution of the case now required a judgment as to the weight of that extrinsic evidence as against the words' plain meaning. Thus Judge Kozinsky complained:

Pacific Gas casts a long shadow of uncertainty over all transactions negotiated and executed under the law of California. . . . [E]ven when the transaction is very sizeable, even if it involves only sophisticated parties, even if it was negotiated with the aid of counsel, even if it results in contract language that is devoid of ambiguity, costly and protracted litigation cannot be avoided if one party has a strong enough motive for challenging the contract. ${ }^{172}$

The more evidence one allows into interpretation, the less certain the outcome. The costs of such uncertainty in the contractual setting can be especially high. A party that wants to organize its behavior in light of the legal effects of a contractual agreement needs to be able to predict how an adjudicator will later interpret that agreement. To the extent thicker interpretive rules reduce predictability, they impose an additional cost on the parties.

In short, plain and literal meaning rules, by relying on a thin interpretive base, reduce the costs of adjudication and make outcomes more predictable, while achieving interpretive accuracy with respect to literal meaning.

So why not always adopt a plain or literal meaning rule? The problem is that the plain and literal meanings of the parties' words might differ significantly from the parties' actual agreement. Kozinski's polemic ignores the risk of correspondence errors. In his Pacific Gas opinion, Traynor quotes section 1636 of the California Civil Code: "A contract must be so interpreted as to give effect to the mutual intention of the parties as it existed at the time of contracting, so far as the same is ascertainable and lawful." ${ }^{173}$ The plain meaning of that statute seems to require California courts to look beyond the plain meaning of the parties' words and actions when evidence indicates that that it does not capture their actual

party losses. 442 P.2d at 643 . The plaintiff was also prepared to introduce extensive evidence that the clause was meant to cover owner losses. See Resp. Pet. for Hearing By the Supreme Court, Pac. Gas \& Elec. Co. v. G. W. Thomas Drayage \& Rigging Co., ______, 1 Civil No. 23738 (filed Oct. 30, 1967).

172 Trident Ctr. v. Connecticut Gen. Life Ins. Co., 847 F.2d 564, 569 (9th Cir. 1988).

${ }^{173} 442$ P. 2 d at 644 n. 5. 
agreement. Thus Traynor expressly rejects plain meaning as the source of contractual obligations.

Some courts have expressed the opinion that contractual obligations are created by the mere use of certain words, whether or not there was any intention to incur such obligations. Under this view, contractual obligations flow not from the intention of the parties but from the fact that they used certain magic words. Evidence of the parties' intention therefore becomes irrelevant.

In this state, however, the intention of the parties as expressed in the contract is the source of contractual rights and duties. A court must ascertain and give effect to this intention by determining what the parties meant by the words they used. ${ }^{174}$

That is exactly what the defendant wanted a chance to prove in Pacific Gas: what the parties meant by the words they used. If the parties truly understood the indemnification clause to cover only third-party property damage — and there were good arguments that they did — the trial court's application of a thin or literal meaning rule resulted in an inaccurate interpretation. The plain meaning of their words did not correspond to their actual agreement.

Although plain meaning rules reduce the costs of adjudication, increase predictability and can provide interpretive accuracy with respect to literal meaning, they create a higher risk of correspondence errors. Plain meaning rules often produce literalist interpretations, and literal meaning is sometimes a poor proxy for the parties' actual agreement, and identification of the parties' actual intentions and understandings is the ultimate goal of contract interpretation. Where there is likely to be a gap, a thicker use meaning rule, despite its extra costs, might be the better design choice.

The question, then, is when the literal meaning of parties' words is more likely to correspond to the parties' actual agreement. This is likely to be so in either of two situations: when parties are aware that their agreement will be subject to a plain meaning rule and make an effort to state in express terms their actual agreement, and when parties have a second-order intention that they be governed by the literal or plain meaning of their words.

Just as responsive parties are likely react to formalistic altering rules by using the formality when they want to achieve the associated legal change, so they are likely to respond to a plain meaning rule by writing in express language the details of their agreement. Doing so entails drafting costs. It takes more time and effort to memorialize every detail of the parties' actual understanding. But for reasons discussed above, the result should be lower litigation costs to achieve accurate and more predictable

${ }^{174} 442$ P.2d at 644 (citing Cal. Civ. Code § 1636). 
outcomes. When it comes to responsive parties, therefore, the choice between thick literal and thin use meaning rules involves the commonly recognized tradeoff between drafting costs at the time of formation and decision costs at the time of adjudication. ${ }^{175}$

Evaluating the tradeoff again raises empirical questions that are not only difficult to answer, but are also likely to have different answers for different types of transactions. One set of questions concerns the relative magnitudes of the costs of drafting and the costs of adjudication under various rules. A second is about predictability. Just how much more predictable are plain meaning rules than thicker forms of interpretation? And how much do parties value that predictability? A third set of questions is about how responsive parties actually are. When are parties likely to react to a plain meaning rule by expressing themselves in clearer terms, reducing the likelihood that a plain meaning rule will result in correspondence errors?

The third question is crucial. Scholars who use economic models commonly assume that sophisticated parties are highly responsive to the incentives legal rules create. Thus Alan Schwartz and Joel Watson have argued that the task of an interpretive rule is not only to accurately recover the parties' actual agreement, but also "to induce parties to take optimal actions ... . to facilitate accurate type identification." ${ }^{176}$ Other writers doubt whether legal interpretive rules much affect parties' behavior. As far back as 1885, writing about the Statue of Frauds, Justice James Stephen and Fredrick Pollock argued:

One cardinal rule, which those who legislate on the common business of life ought always to bear in mind, is that the power of law to control conduct is small, and is constantly exaggerated. Laws ought to be adjusted to the habits of society, and not aim at remoulding them. The cases in which any law is actually enforced are infinitesimally small in number in comparison with those in which it has no effect whatsoever. Custom, and what is called common sense, regulate the great mass of human transactions. ${ }^{177}$

${ }^{175}$ See, e.g. Jody S. Kraus \& Robert E. Scott, Contract Design and the Structure of Contractual Intent, 84 N.Y.U. L. Rev. 1023, _____ [Part III] (2009).

${ }^{176}$ Alan Schwartz \& Joel Watson, Conceptualizing Contract Interpretation, 42 J. LEGAL STUD. 1, 4 (2013).

177 James F. Stephen \& Frederick Pollock, Section Seventeen of the Statute of Frauds, 1 L. Q. Rev. 1, 6 (1885). See also, famously, Stewart Macaulay, Non-Contractual Relations in Business: A Preliminary Study, 28 AM. SOC. REV. 55 (1963). 
In fact, this is likely another area in which generalizations are difficult. We should expect the incentive effects of interpretive rules to depend in large part on who the parties are, the nature and stage of the transaction, and the type of communication at issue.

There is a second situation in which a plain or literal meaning rule perforce captures the parties' actual intent and agreement: when parties have agreed to be governed by the plain or literal meaning of their words. This is how Williston explains why integrated writings should be subject to plain meaning interpretation:

[I]n case of a writing wholly informal in character [i.e., not under seal], but which nevertheless was adopted by the parties as a statement of their bargain [i.e., integrated], the same principle is applicable. The parties have assented to those words as binding upon them. In an ordinary oral contract or one made by correspondence, the minds of the parties are not primarily addressed to the symbols which they are using; they are considering the things for which the symbols stand. Where, however, they incorporate their agreement into a writing they have attempted more than to assent by means of symbols to certain things, they have assented to the writing as the adequate expression of the things to which they agree. ${ }^{178}$

When parties have a second-order intention that a writing's plain meaning shall govern, there is a sense in which the content of their actual agreement is just that plain meaning-even if at the time of formation one or both had a different understanding of it. Just as a game show contestant has chosen the object behind Door Number One, whether it turns out to be a goat or a trip to Paris, so parties might choose to be governed by the plain meaning of their words, whatever that plain meaning turns out to be. Where the parties have such a second-order intention, the accurate identification of plain meaning automatically achieves correspondence accuracy.

Again it is an empirical question whether or when parties have such second-order intentions. The easy case is when parties have expressly agreed to a plain or literal meaning rule-when parties say in their agreement that they wish to be governed by its plain or literal meaning. For example:

The Parties' legal obligations under this . . . Agreement are to be determined from the precise and literal language of this ... Agreement and not from the imposition of state laws attempting to impose additional duties of good faith, fair dealing or fiduciary

${ }^{178} 2$ Williston (1st ed.) $\S 606,1165$. 
Klass: Contract Exposition and Formalism

obligations that were not the express basis of the bargain at the time this Agreement was made. ${ }^{179}$

Another easy case is where the parties expressly agree to a thick usemeaning rule. In Corthell v. Summit Thread Co., for example, a Maryland court considered an employment agreement that "specified that the terms of the contract were 'to be interpreted in good faith on the basis of what is reasonable and intended, and not technically.'"180

The more interesting cases are those in which the parties do not say one way or the other. In these situations, courts might look to other evidence of or proxies for the parties' second-order agreement to be governed by their words' plain meaning. As noted in section 2.2.3 above, US courts commonly use integration as such a proxy, perhaps based on the Willistonian presumption that parties who adopt an integrated writing probably to intend to be governed by it plain meaning. Whether such a presumption is correct turns in part on the rules that determine when a writing is integrated, which are considered in Part Four.

A plain meaning rule that parties have not chosen for themselves is likely to generate correspondence errors when parties are unresponsive to the legal rule, and so fail to express their agreement or intentions in clear terms. ${ }^{181}$ The rules of contemporary contract law attach legal consequences to a wide variety of nonjuristic acts—-making an agreement, saying something about the quality of goods, manifesting an intention to perform despite the nonoccurrence of a condition, expressing doubts that one will perform, and so forth. Sometimes when parties satisfy these nonjuristic altering rules they are not thinking about the legal consequences of their words or actions. When this is the case, parties are more likely to speak elliptically, relying on their shared background and understanding of the transaction. ("Go ahead, you're all right; get your men out and don't let that worry you.") In such circumstances, the literal meaning of the parties' words - even if those words appear in a writing —is much less likely to correspond to the speaker's actual intentions or to the hearer's reasonable

${ }^{179}$ Kraus \& Scott, supra note 175, at 1102 n. 274 (quoting E. I. du Pont de Nemours \& Co. and EarthShell Corp., Alliance Agreement art. 12(h), at 7 (July 25, 2002), available at: http://contracts.onecle.com/earthshell/dupont.collab.2002.07.25.shtml). 180167 A. 79, 80 (Me. 1933). Oddly, from my perspective, Kraus and Scott do not pay much attention this clause in their analysis of the case, but instead criticize the Maryland court for excusing an express condition in the contract. Kraus \& Scott, supra note 175 at 1086.

${ }^{181}$ A plain meaning rule is also likely to generate correspondence errors when drafting costs deter responsive parties from expressing their agreement in literal terms. Such errors are arguably less problematic, as the parties themselves have chosen the risk of correspondence error. 
understanding. If the law nonetheless adopts a plain meaning rule to determine their meaning, the salient tradeoff is no longer increased drafting costs in exchange for cheaper adjudication and greater predictability. It is, rather, accepting a greater likelihood of correspondence error in exchange for a cheaper adjudication. It is much less obvious that this is a tradeoff lawmakers should make.

In short, to the extent we care about accuracy, thick use meaning or actual agreement rules are desirable when we expect parties to be unresponsive to the rule. When this is the case is again an empirical question. With respect to contract formation, easy cases include implied-infact contracts and many oral agreements. Possible waivers and repudiations are also good candidates for thicker interpretive rules. Somewhat more difficult cases are those in which the parties have expressed all or part of their agreement in writing, but it is not obvious that they were treating that writing as a legally effective document. More generally and crucially, whenever an altering rule specifies a nonjuristic altering act, it is always possible that parties who perform it are not thinking about legal consequences. In such circumstances, thicker use meaning altering rules are more likely to capture the speaker's intent and the hearer's reasonable understanding.

A final factor to consider in thinking about the choice between plain meaning rules and thicker use meaning or actual agreement rules is the likely effects of each on the parties' extralegal relationship. As I have observed, many contractual transactions depend for their success on more than the law of contracts. Honor, friendship, community, reputation, repeat play, a moral sense and other nonlegal sources of trust often add considerable value to a transaction. It is unlikely that legal enforcement would have no effect on these extralegal aspects of exchange relationships. It is not, however, a priori obvious what the effect will be. With respect to rules of interpretation, Lisa Bernstein has argued that some thicker rules can interfere with the development of extralegal forms of assurance. ${ }^{182}$ The UCC's permissive rules for course of dealings and course of performance evidence, Bernstein argues, are likely to deter parties from the sort of cooperative flexibility that generate extralegal forms of trust. A responsive party might worry that its failure to insist on strict performance will later be used to interpret its agreement, thereby eroding its legal entitlement. These thick interpretive rules thereby discourage the flexible give-and-take that characterizes extralegal forms of trust. Others have argued that the drafting incentives plain meaning rules create pose their own threat to extralegal trust. Richard Posner, invoking his years of experience on the bench, highlights the costs of writing highly detailed contracts:

${ }^{182}$ Lisa Bernstein, Merchant Law In a Merchant Court: Rethinking the Code's Search for Immanent Business Norms, 144 U. PA. L. REV. 1765, 1807-15 (1996). 
Klass: Contract Exposition and Formalism

There is frequent conflict between lawyer and client over how detailed a contract should be, the former pushing for the inclusion of endless protective clauses and the latter worrying that pressing for such clauses will not only protract negotiations and increase legal fees but also make him seem a sharpie and kill the deal. Better that the contract should be kept reasonably short, and that if an unforeseen contingency arises it be resolved in a commonsensical fashion. It is reassuring to think that if one's contract should come to grief the court will straighten matters out in a "reasonable" way rather than by recourse to legal technicalities. Businessmen want judges to resolve interpretive issues in the way that a reasonable businessman would. ${ }^{183}$

To the extent plain meaning rules push parties to spell out in advance every aspect of their transaction, they too might deter the development of extralegal forms of assurance. ${ }^{184}$ Again we have reached a point where the right answer depends on empirical facts. And again the relevant costs are likely to turn on who the parties are, the type of transaction, market conditions, and the like.

The above discussion can be summarized as a list of factors relevant to deciding when to apply plain meaning rules and when thicker use meaning rules are more appropriate. In adopting per se rules for the admissibility of any given type of interpretive evidence, lawmakers should consider (1) gains in interpretive accuracy; (2) additional costs of adjudication; (3) savings in the costs of drafting; (4) reductions in the predictability of interpretive outcomes; and (5) relational costs or benefits; and (6) the likelihood of correspondence errors. The factors are not independent of one another. If parties are responsive, for example, thin interpretive rules result in more detailed written agreements, thereby reducing the gains in correspondence accuracy to be had from thicker forms of interpretation. All six factors are likely to depend on who the parties are, the transaction type, market conditions, and the like. Generally speaking, however, plain meaning rules are likely to work when parties are

${ }^{183}$ Richard A. Posner, The Law and Economics of Contract Interpretation, 83 Tex L. Rev. 1581, 1607 (2005). Posner attributes what he sees as the excesses of New Formalism "in part to the fact that fewer and fewer legal academics have significant experience in the 'real world' of contract drafting or business litigation." Id. at 1592.

${ }^{184}$ For more on the question, see Omri Ben-Shahar, The Tentative Case Against Flexibility in Commercial Law, 66 U. CHI. L. ReV 781 (1999) (providing a formal argument that the use of past practices in interpretation both encourages and deters flexibility, and that in theory these effects cancel each other out). 
attuned to the legal rules that govern their transaction-whether because they are performing a juristic act, because they are responsive to the default or mandatory rule, or because they have agreed to a plain meaning rule themselves. When an altering rule does not presuppose parties' intent to effect a legal change and parties are not likely attuned to the legal effects of their words and acts, thicker use meaning or actual agreement rules are preferable.

One more comment on the above analysis. I have been treating both interpretive and correspondence accuracy as if they were simple goods. But theorists disagree on just how valuable accuracy is-on how to weigh the accuracy gains of thicker interpretive rules against their various costs. Schwartz and Scott, for example, argue that sophisticated risk-neutral firms do not care about accuracy in any given case. "A risk-neutral party cares about the mean of the interpretation distribution but not the variance. ${ }^{\prime 185}$ So long as interpretive errors are as likely to benefit as to harm the firm, the cost of those inaccuracies will in the long run even out. From the perspective of a risk-neutral firm, "it is good enough that courts get things right on average. ${ }^{\prime 186}$ Schwartz and Scott deploy this argument in support of a very thin default rule of interpretation. For risk-neutral firms, the accuracy gains from admitting additional evidence are unlikely to justify the additional costs in litigation. "Therefore, the best interpretive default for firms is textualist when the issue is what their contract language meant." ${ }^{\prime 187}$

Schwartz and Scott's argument has among its premises not only that firms are risk neutral, but also that the primary goal in enforcing contracts between them is to maximize the joint gains of trade. "The contract law of commercial parties is about efficiency." ${ }^{\prime 188}$ But this is hardly the only function contract enforcement might serve, whether for contracts between firms or for contracts among other types of parties. A theorist who considers an important function of contract law to be enforcing parties' moral obligations, achieving a just outcome between the parties, or supporting the moral culture of making and keeping agreements is likely to attach greater value to interpretive accuracy than do Schwartz and Scott. Of course it is no surprise that the optimal rules of contract law depend in part on the broader functions that contract law is meant to serve. But it is worth keeping in mind that the value of interpretive accuracy depends also on purpose of contract enforcement more generally.

${ }^{185}$ Schwartz \& Scott, supra note 89 at 576.

186 Id. at 577.

187 Id. at 583

${ }^{188}$ Id. at 550-56. 
Klass: Contract Exposition and Formalism

\section{Application: The Parol Evidence Rule and Integration}

As E.B. and Katherine White famously observed, "Humor can be dissected, as a frog can, but the thing dies in the process and the innards are discouraging to any but the purely scientific mind." ${ }^{189}$ The same can be said of legal theory. Having dissected the rules of contract exposition, perhaps to death, this Part applies the theory to critically examine an important but understudied part of the living parol evidence rule: how courts decide when an agreement is integrated. I have already discussed the connection between the parol evidence rule and plain meaning formalism. Most courts treat integration as sufficient to trigger plain meaning interpretation of a writing. Here I am interested in a different aspect: the rule for determining that a writing is integrated, or the parol evidence altering rule.

The basic idea of the parol evidence rule is that sometimes a writing should be given more weight than other evidence of the parties' contractual agreement. If the adjudicator finds the writing to be fully integrated, the parties may not attempt to prove terms that do not appear in it. If the adjudicator finds that the writing is partially integrated, parties may not attempt to prove terms contrary to those in the writing. In either case, in most US jurisdictions integration triggers one or another plain meaning rule, limiting the extrinsic evidence that can go into interpretation of the writing.

These are the legal effects of integration. What interests me here is the rule for deciding whether a writing is integrated_rules that scholars often neglect. For example, although Jody Kraus and Robert Scott argue at length that most sophisticated commercial parties want courts to apply formalist rules of interpretation to their integrated agreements, they say nothing about how courts should tell when a writing is integrated. They observe only that courts "have devised various neutral tests for determining whether parties intended to integrate part or all of their agreement into a final, legally enforceable writing." ${ }^{190}$ But these rules are hardly neutral, and they vary across jurisdictions. A theory of contract exposition should have something to say about the altering rules that effect plain meaning rules.

The modern view, which dates to Wigmore, ${ }^{191}$ holds that absent a seal, integration depends on the parties' intentions. A writing is integrated when and only when the parties have agreed that it shall be a final statement of some or all of the terms of their contract. As Williston explained: "The parol evidence rule does not apply to every contract of

${ }^{189}$ A Subtreasury of American Humor: Preface xvii (E.B. White and Katharine S. White, eds. 1941). The quote is usually attributed only to E.B. White.

${ }^{190}$ Kraus \& Scott, supra note 175 , at 1047.

191 See, e.g., 5 Wigmore (2d ed.) §§ 2401, at 240. 
which there is written evidence, but only applies where the parties to an agreement reduce it to writing, and agree or intend that that writing shall be their agreement." ${ }^{192}$ It its 1986 report on the parol evidence rule, the English Law Commission emphasized this agreement-based understanding to reach a fairly radical conclusion.

[A] lthough a proposition of law can be stated which can be described as the "parol evidence rule" it is not a rule of law which, correctly applied, could lead to evidence being unjustly excluded. Rather, it is a proposition of law which is no more than a circular statement: when it is proved or admitted that the parties to a contract intended that all the express terms of their agreement should be a recorded in a particular document or documents, evidence will be inadmissible (because irrelevant) if it is tendered only for the purpose of adding to, varying, subtracting from or contradicting the express terms of a contract. We have considerable doubts whether such a proposition should properly be characterized as a "rule" at all. ${ }^{193}$

If integration is merely one contract term among others, what has traditionally been called the "parol evidence rule" is no more than enforcement of the parties' agreement-hence not a rule at all. It is not the existence of the writing that matters, but the fact that the parties have agreed that it shall serve as a final statement of some or all of the terms of their agreement. ${ }^{194}$

Despite its rhetorical power, the Law Commission erred in concluding that an agreement-based parol evidence rule is not in fact a rule. First, if parties have the power to attach special significance to a writing, it is only because contract law gives them that power. That is, it is only because there is a rule of construction that gives legal effect to agreements to integrate. Second, at least in the United States the parties' agreement to a writing as a final statement of some or all terms does more than exclude extrinsic evidence of contrary or additional terms. It also triggers plain meaning interpretation, whether or not the parties have

1922 Williston (1st ed.) $\S 633,1225$ (emphasis added).

${ }^{193}$ Law Commission, Law of Contract: The Parol Evidence Rule, § 2.7, at 8 (Law Com. No. 154, 1986) Cmnd 9700 (hereinafter "Law Commission Report").

${ }^{194}$ Thus on the agreement-based view, parties could just as well integrate an oral exchange-by agreeing that the exchange is a final statement of some or all of their agreement. Id. $\S 2.20$, at 14-15 (citing commentators who hold this view). 
agreed to that interpretive rule. ${ }^{195}$ This rule of construction extends beyond interpretation of the parties' agreement. Third, even if integration is a matter of agreement, we require a rule that says how such agreement must be expressed or evidenced if it is to be legally effective. We require, in other words, a parol evidence altering rule. ${ }^{196}$

US courts recognize two ways parties can effectively express or evince their shared intent to integrate. ${ }^{197}$ First, parties can include in the writing a merger clause. A merger clause expressly says that the parties intend the writing as the final statement of some or all terms. For example:

This instrument embodies the whole agreement of the parties. There are no promises, terms, conditions, or obligations other than those contained in this contract, and this contract shall supersede all previous communications, representations, or agreements, either verbal or written, between the parties. ${ }^{198}$

Second, if the writing contains no merger clause, courts look to whether the writing appears to be intended as final statement of some or all terms of the parties' agreement. Thus the Second Restatement provides, "[w] here the parties reduce an agreement to a writing which in view of its completeness and specificity reasonably appears to be a complete agreement, it is taken to be an integrated agreement." ${ }^{199}$ There is an important difference between these two cases. When the parties agree to a merger clause, they say how they intend the writing to be used. When an adjudicator finds integration absent a merger clause, it relies not on the communicative content of what the parties said about integration, but on the adjudicator's interpretation of their likely intentions or understandings absent such a communication. In the one case, the decision maker can look to their acts of agreement. In the other, the rule looks to their actual agreement in the absence of such acts.

195 The Law Commission expressly rejected applying different rules of interpretation to integrated writings under English law. Id. $\S \S 1.2 \& 2.7$ at 2 $\& 8$.

${ }^{196}$ Putting the question in these terms clarifies that there is a default as well. In US law, the generic default is that a writing is not integrated.

${ }^{197}$ Here a caveat is in order: The law governing the parol evidence rule is less clear than one might wish. As Farnsworth observes with respect to the Williston-Corbin divide, discussed below: "Surprisingly little light is shed on the problem by the hundreds of decisions resolving the issue of whether an agreement is completely integrated. Opinions often fail to set out the text of the writing in full, and each case turns on its own peculiar facts."

Farnsworth, supra note $149, \S 7.3$,

198 1A Williston on Contracts 4th Forms $\S 33 \mathrm{~F}: 2$ (2016).

${ }^{199}$ Restatement (Second) of Contracts § 209(3) (1981). 
US authorities differ on what interpretive evidence an adjudicator may consider to determine whether a writing is integrated. ${ }^{200}$ Jurisdictions that adopt so-called hard parol evidence rules, commonly associated with Williston, employ a thin test for integration. If a writing appears on its face to be a complete statement of all the parties' obligations, it is fully integrated. "[T]he contract must appear on its face to be incomplete in order to permit parol evidence of additional terms." ${ }^{201}$ Jurisdictions with socalled soft parol evidence rules, associated with Corbin, employ a thicker test. The decision maker should always consider all available evidence of the parties' intent, even if the writing includes a merger clause. "If the offered evidence is relevant and credible on the issue of either interpretation or integration, it should never be excluded, for the reason that, whatever are the written words, those issues are always debatable."202 The most recent edition of Williston acknowledges that the Second Restatement adopts a thick test for integration, but reports that the thin test remains the majority rule. ${ }^{203}$ The most recent edition of Farnsworth's treatise, on the contrary, suggests that "the prevailing view [is] that other evidence, including evidence of prior negotiations, is still admissible to show that a writing was not intended as a final expression of the terms it contains." ${ }^{204}$ Under either rule extrinsic evidence may be introduced to show an invalidating cause such as misrepresentation, duress or mistake.

What should we make of this collection of parol evidence altering rules? The theory developed in this article suggests several critical observations.

First, it is somewhat odd that US law does not provide a formality with which parties can signal their intent to integrate. The parol evidence rule is a power-conferring one. It allows parties to determine by agreement the legal effects of a writing. Similarly, a merger clause is commonly a juristic act. It says that the parties intend, by the very expression of that intent, that the law shall treat the writing as the definitive statement of some or all of their legal obligations. A short, canonical form with which to express such an intent would be extremely useful. Although form books are

${ }^{200}$ For a discussion of the differences between hard and soft parol evidence rules, see Posner, supra note 114, passim.

2012 Williston (1st ed.) §633, 1226.

202 Arthur L. Corbin, The Interpretation of Words and the Parol Evidence Rule, 50 Cornell L.Q. 161, 173 (1965). See also Arthur L. Corbin, The Parol Evidence Rule, 53 Yale L.J. 603, 642 (1944) ("Just as no written document can prove its own execution, so none can prove that it was ever assented to as either a partial or a complete integration, supplanting and discharging what preceded it.").

20311 Williston on Contracts $\S 33: 17$, "Evidence on the issue of whether an integration exists; traditional and modern views," at (4th ed. XXXX).

${ }^{204}$ Farnsworth, supra note $149, \S 7.3$, (2004). 
full of possible merger clauses, there exists in US law no short, effective, standard formula, comparable to "F.O.B." or "as is," that parties can use to integrate a writing. The seal once served such a purpose. But it was always a blunt instrument, as putting a writing under seal had other legal effects as well. A non-requisite formality—such as printing the words "Final Statement of All Terms" or "Final Statement of Terms Included" at the top of a document-would provide parties who wish to integrate a writing a useful tool for doing so. That we have no such formality is a historical accident, attributable perhaps to the general decline of formalities in the early twentieth century.

Second, it is more than a little curious that courts are willing to find writings to be integrated absent merger clauses. Why have a rule that permits courts to look for parties' actual but unexpressed intent to integrate? Why not require parties sophisticated enough to agree to integrate a writing to express their agreement in words?

An actual agreement altering rule instructs adjudicators to look beyond parties' words to other evidence of their beliefs and intentions. Generally speaking, such a rule is desirable when parties' words are unlikely to reflect their actual agreement. Thus the comments to UCC section 2-202 explain that course of dealings, course of performance and usage of trade are always admissible "in order that the true understanding of the parties as to the agreement may be reached." ${ }^{205}$ In short, the reason to adopt actual agreement rules is to avoid Type II correspondence errors: instances in which parties intend an outcome, but fail to say so.

But parties sophisticated enough to intend a writing as a final statement of terms would likely be responsive to a rule requiring them to say so. Type II correspondence errors are unlikely to be much of a problem with respect to integration. And there are significant costs to the actual agreement rule. First, it is not obvious that, absent a merger clause, ex post adjudicators are very good at identifying the parties' objective intent with respect to integration-no matter what evidence they are allowed to consider. If they are not, an actual agreement rule might generate more Type I and II interpretive errors-false positives and false negative-than the Type II correspondence errors it avoids. Second, an actual agreement rule does so with higher costs of adjudication and reduced predictability of outcomes. Third, requiring parties who wish to integrate a writing to say so can put nonsophisticated parties on notice of the legal effects of the writings they sign, reducing Type I correspondence errors.

A third even more puzzling feature is the combination in hard parol evidence rules of an actual agreement altering rule with evicentiary formalism. A rule that limits evidence of integration to the document itself might make sense when parties expressly say that a writing is the final statement of terms, especially in a negotiated agreement between parties

${ }^{205}$ U.C.C. § 2-202 cmt. 2. 
represented by counsel. Parties who are sophisticated enough to knowingly agree to a merger clause are likely to take extra care to ensure that their words match their intentions-including the words of the merger clause. Absent a merger clause, however, it is not obvious why courts should not consider extrinsic evidence of the parties' actual intentions with respect to integration. As Wigmore argued,

The document alone will not suffice. What it was intended to cover cannot be known till we know what there was to cover. The question being whether certain subjects of negotiation were intended to be covered, we must compare the writing and the negotiations before we can determine whether they were in fact covered. ${ }^{206}$

Without the parties' clear statement one way or another, the interpretation of their actual agreement as to the legal effect of a writing is necessarily uncertain. Relevant extrinsic evidence should always be of value in ascertaining the parties' intent to integrate.

So why does contemporary contract law not require parties who intend a writing as a final statement of their agreement to add a few words to that effect? And why don't jurisdictions with hard parol evidence rules at least look to extrinsic evidence of the parties' intent to integrate when the parties have not said one way or another? Although ex post justifications are always possible, the explanation of these components of the parol evidence altering rule probably lies in the rule's history. Whereas today agreement-based accounts of the rule are the norm, the rule's origins can be traced to two other features of early English law: the best evidence rule and a desire to control the jury. The best evidence rule established an evidentiary hierarchy: written evidence, which was commonly under seal, could not be contradicted by oral evidence. "An inferior matter [was] admissible neither in opposition to nor in substitution for superior." ${ }^{207}$ This was a simple rule of evidence, not agreement. The writing's weight came not from the parties' intentions, but from its form. At the same time, as Wigmore observes, there was a judicial desire "to keep from the jury all alleged oral transactions which might be misused by them to overturn the words of a writing." ${ }^{208}$

If the parties were allowed to put in averments extraneous to the writing, it must go to the jury, and there was no telling what the jury

\footnotetext{
${ }^{206}$ Wigmore (2d ed.) $\S 2430$.

207 Salmond, The Superiority of Written Evidence, 6 L. Q. Rev. 75, 76 (1890). See also 5 Wigmore (2d ed.) § 2426, 299-300.

${ }^{208} 5$ Wigmore (2d ed.) $\S 2426,298$.
} 
Klass: Contract Exposition and Formalism

might do; but if the judges took exclusive charge, they could better control the situation. ${ }^{209}$

Mistrust of the jury required a rule that did not merely give the written word greater weigh, but rendered it dispositive.

These historical roots suggest reasons for the contemporary parol evidence altering rule that have little to do with enforcing the parties' agreement with respect to integration. Allowing courts to find integration in the absence of a merger clause, based only on a writing's apparent completeness, effectively puts a thumb on the scale in favor of integration, and thereby also plain meaning interpretation. If a writing looks to the judge like a final document, she has the power to decide that the writing is legally controlling, to interpret it according to its plain meaning, and to avoid sending questions of interpretation to the jury. The altering rule is structured not only to effectuate the parties' intentions, but also to favor judicial plain meaning interpretation of certain documents.

One reason to adopt such a rule might be an abiding belief that writings are more reliable evidence than other types of parol evidence, and especially testimony of oral agreement. ${ }^{210}$ Another might be distrust of the jury when it comes to the interpretation and construction of contractual agreements, or the evaluation of parol evidence. ${ }^{211} \mathrm{~A}$ third might Fuller's channeling function. A rule that favors a finding of integration puts responsive parties on notice that they should be careful with the words they write down. A fourth might be a belief that plain meaning rules are the majoritarian default for contractual writings. Scott and Schwartz, for example, agree that parties should be able to decide how their rules are construed, but rather than focusing on the altering rule, they emphasize finding the right default. ${ }^{212}$ If one believes that most parties prefer plain

${ }^{209} / d$

${ }^{210}$ See, e.g., Edwin W. Patterson, The Interpretation and Construction of Contracts, 64 Colum. L. Rev. 833, 846 (1964) ("[T] he written instrument is a more reliable expression of the meaning of their contract than one party's not disinterested memory of his or the other party's prior oral utterances.").

${ }^{211}$ See Charles T. McCormick, The Parol Evidence Rule as a Procedural Device for Control of the Jury, 41 Yale L.J. 365 (1932).

${ }^{212}$ For example:

A commitment to party sovereignty regarding the contract's substantive terms implies a further commitment to party sovereignty regarding the interpretive style an adjudicator should use to find the substantive terms. Party preferences regarding judicial interpretive styles can differ. Therefore, interpretive styles should be defaults. The relevant question, then, is what should be the majoritarian default. Put another way, the issue is not what interpretive style is best calculated to yield the correct answer. Rather, the issue is what 
meaning rules, one way to satisfy their preference is a rule that favors a finding of integration.

I am skeptical as to whether these reasons are enough to justify the actual agreement parol evidence altering rules most courts employ, and especially rules that exclude extrinsic evidence of the parties' intent. Whether they are or not, however, the above analysis demonstrates three things. First, contra the Law Review Commission, even if integration is merely a matter of agreement, there remains such a thing as a parol evidence rule. It is the rule of construction that determines what evidence of the parties' intent suffices to for a finding of integration. Second, lawmakers would do well to provide sophisticated parties with a formality they could use to integrate their writings. Third, the existing test for integration strongly suggests that the rule is not only about realizing the parties' intent at the lowest possible cost. If that were the only goal, courts would require parties to say when they intended a writing as integrated, or courts would at least consider extrinsic evidence of their intent. The parol evidence altering rules one finds on the books are designed to give special weight to the plain meaning of the written word.

Finally, it is worth thinking a bit more about party responsiveness, and especially about how courts should determine whether contracts of adhesion between sophisticated and nonsophisticated parties are integrated.

The Draft Restatement (Third) of Consumer Contracts suggests a very different parol evidence altering rule for such agreements. Under the Draft's rule, standard terms and merger clauses in such agreements would generate only a weak presumption of integration. ${ }^{213}$ That presumption would then be "rebutted when the standard contract terms contradict or unreasonably limit an affirmation or promise, which is made part of the basis of the bargain between the business and the consumer." ${ }^{214}$ Such a rule would treat the altering acts courts commonly use to find integration, including merger clauses, as highly defeasible-so defeasible as to arguably gut the parol evidence rule of its force. A consumer could always introduce extrinsic evidence of contrary material terms to demonstrate that she did not consent to the writing as a final statement of terms.

interpretive style would typical parties want courts to use when attempting to find the correct answer.

Schwartz \& Scott, supra note 89 at 569. Oddly, Schwartz and Scott say nothing about what parties should do to contract around their preferred plain meaning default.

${ }^{213}$ Draft Restatement (Third) of Consumer Contracts, Council Draft No. 3, $\S 8(\mathrm{a}) \&(\mathrm{~b})(2017)$.

${ }^{214}$ Id. § 8(c). 
It is unclear whether the case law fully supports this proposed rule. $^{215}$ It is, however, supported by the broader theory of the Draft Third Restatement, and by the design considerations identified in Part Three of this article. The Draft emphasizes evidence that consumers do not read most of the terms in contracts of adhesion.

It is presumed that standard contract terms do not affect the contracting decisions of a substantial number of consumers. This presumption applies most forcefully when the standard contract term is part of a long-list of fine-print terms; it is rebutted when the standard contract term is, e.g., a conspicuous price or delivery fee. ${ }^{216}$

In the language of the above analysis, consumers often are not responsive to the terms in the writings to which they agree, much less to the legal rules that govern their agreements. These are circumstances in which evidentiary formalism and plain meaning rules are likely to cause correspondence errors-in which the literal or plain meaning of a writing less likely to correspond to one party's actual intent and understanding. The solution is to always permit the decision maker to consider evidence from outside the writing. In practice, it matters little whether this is stated as an easily defeasible altering rule, which is the approach of the Draft Third Restatement takes, or as a thick interpretive rule for merger clauses, which is how Corbin frames his preferred rule. Both are ways to avoid interpretive formalism when determining whether a consumer contract of adhesion is integrated.

\section{Conclusion}

When courts are asked to adjudicate disputes about what contractual agreements mean, they often recite lists of familiar maxims so general and sometimes conflicting that they can appear meaningless. "The fundamental, neutral precept of contract interpretation is that agreements are construed in accord with the parties' intent." 217 "The best evidence of what parties to a written agreement intend is what they say in their writing." 218 "The intent of the parties as expressed in writing is determined from the language used interpreted in the light of the situation of the parties

${ }^{215}$ Although the Reporters' Notes to section 8 discuss case research, many of the cases they cite do not deal specifically with consumer contracts, but articulate soft parol evidence rules more generally. The rule is, however, consistent with Restatement (Second) of Contracts § 211(3) (1981).

${ }^{216}$ Id. $\S 5$, cmt. 6, at 56-57.

217 Greenfield v. Philles Records, Inc., 98 N.Y.2d 562, 569 (2002).

${ }^{218}$ Slamow v. Del Col, 79 N.Y.2d 1016, 1018 (1992). 
and the circumstances connected with the transaction." 19 "The meaning of a contract is found by examination of the entire instrument and not by viewing clauses or phrases in isolation." ${ }^{220}$ "In reviewing contract language for other possible interpretations, we are required to interpret the language in an ordinary and popular sense as would a person of average intelligence and experience." ${ }^{221}$ "[S]trong extrinsic evidence indicating an intent contrary to the plain meaning of the agreement's terms can create an ambiguity - provided that the evidence is objective."222

This article has attempted to locate these and other rules within a general account of contract exposition. The above discussion provides a rubric for evaluating the rules that govern the legal effects of contracting parties' words and actions. Too often the design question is framed as a simple choice between Willistonian formalism and Corbinite contextualism. Although that choice is central, it is not simple. The right approach to contract interpretation depends on the rules of contract construction, and especially on the altering rules that determine when a default legal state of affairs no longer pertains. Deciding on the correct altering rule requires considering multiple design questions that are unlikely to have the same answers across all types of transactions, legal questions, and altering acts. Salient questions include: Should the altering rule employ a legal formality, either as a sufficient to effect a legal change or as both necessary and sufficient to do so? If lawmakers adopt a formalistic altering rule, what formal act should it require? What should their legal effects be, and should they be defeasible or nondefeasible? If lawmakers opt for an interpretive rule, how much evidence of what types should interpreters consider? Should they seek the literal meaning, common or local, of the parties' words, their use meaning, with or without extrinsic evidence, or the parties' actual intentions and understandings? And what circumstances should suffice to trigger more or less formalist interpretive rules? Adjudicators need not answer all these questions in every case. What is important is that in hard cases they be able to locate the question before them within the logical space of contract exposition.

21919 Perry St., LLC v. Unionville Water Co., 294 Conn. 611, 623 (2010) (internal punctuation omitted).

${ }^{220}$ U.S. Fid. \& Guar. Co. v. Budget Rent-A-Car Sys., Inc., 842 P.2d 208, 213 (Colo. 1992).

${ }^{221}$ Funeral Fin. Sys. v. United States, 234 F.3d 1015, 1018 (7th Cir. 2000).

${ }^{222}$ Bock v. Computer Associates Int'I, Inc., 257 F.3d 700, 708 (7th Cir. 2001). 